\title{
High-performance triazole-containing brush polymers via azide-alkyne click chemistry: a new functional polymer platform for electrical memory devices
}

\author{
Sungjin Song ${ }^{1,3}$, Yong-Gi Ko ${ }^{1,3}$, Hoyeol Lee ${ }^{1,3}$, Dongwoo $\mathrm{Wi}^{1}$, Brian J Ree ${ }^{1}$, Yongrong $\mathrm{Li}^{2}$, \\ Tsuyoshi Michinobu ${ }^{2}$ and Moonhor Ree ${ }^{1}$
}

Two series of well-defined brush polymers bearing a triazole moiety on each bristle were prepared from the click chemistry reactions of a poly(glycidyl azide) (PG) and a poly(4-azidomethylstyrene) (PS) with alkyne derivatives. The thin-film morphologies and properties, especially electrical memory performances, of these triazole-containing brush polymers were investigated in detail. The brush polymers with a triazole ring substituted with an alkyl or alkylenylphenyl group in the bristle exhibited only dielectric characteristics. By contrast, the other brush polymers bearing a triazole ring substituted with phenyl or its derivatives with a longer $\pi$-conjugation length in the bristle demonstrated excellent unipolar permanent memory behaviors with low power consumption, high ON/OFF current ratios and high stability and reliability under ambient air conditions. Furthermore, their memory type could be tuned to $p$ - or $n$-type by the incorporation of an electron-donating or -accepting group into the phenyl unit linked to the triazole moiety. Overall, this study presents the first demonstration of the azide-alkyne click chemistry synthesis of triazole moieties with substituent(s) that exhibit a resonance effect; this approach is a very powerful synthetic route to develop electrical memory polymers suitable for the low-cost mass production of high-performance, polarity-free programmable memory devices.

NPG Asia Materials (2015) 7, e228; doi:10.1038/am.2015.130; published online 4 December 2015

\section{INTRODUCTION}

Since click chemistry was introduced in $2001,{ }^{1}$ it has become one of the most powerful synthetic tools to develop functional polymers. ${ }^{2}$ Through click chemistry reactions, desired functional moieties can be easily incorporated into polymers as side groups, $\mathrm{pr}$ oducing functionalized polymers. ${ }^{2-6}$ In particular, $\mathrm{Cu}(\mathrm{I})$-catalyzed azide-alkyne cycloaddition has been well established as a representative click chemistry reaction capable of selectively combining two components via covalent bonds in excellent yields. ${ }^{1-7}$ This click reaction, however, has some drawbacks, such as the requirement of a metal-based catalyst for achieving a high reaction conversion and controlling regioselectivity, the explosive nature of some azide substances and the negative effects of the formed triazole ring on solubility and other properties such as electronic and optoelectronic properties. ${ }^{8}$ Extensive effort has been devoted to overcome such drawbacks, resulting in the development of metal-free azide-alkyne click chemistry as well as azide-free click chemistry. ${ }^{9-15}$ Nevertheless, the drawbacks arising from triazole ring formation have not yet been solved.
As previously discussed, triazole rings can potentially introduce drawbacks into the development of functional polymers; however, they hold elements advantageous to high-performance electrical memory polymers. ${ }^{16}$ As a pseudo-heteroaromatic ring, the triazole ring contains three nitrogen atoms with lone-pair electrons exhibiting high hole affinity, allowing the ring to act as a charge trap site. The exploitation of the charge-trapping characteristic and the ease of forming the triazole ring via azide-alkyne click chemistry can assist in the development of new high-performance electrical memory polymers.

Recently, electrical memory polymers have attracted extensive attention from academia and industry over the past 15 years as potential alternatives to silicon- and metal-oxide-based electrical memory materials, because they can be processed into miniaturized dimensions and multi-stack layer structures with ease and because they possess highly tunable properties controlled by well-defined chemical synthesis. ${ }^{16-19}$ Thus far, numerous electrical memory polymers composed either of fully $\pi$-conjugated backbones ${ }^{17-19,21-25}$ or of nonconjugated backbones bearing only electron-donor units or

\footnotetext{
${ }^{1}$ Department of Chemistry, Division of Advanced Materials Science, Pohang Accelerator Laboratory, Polymer Research Institute, and BK School of Molecular Science, Pohang University of Science and Technology, Pohang, Republic of Korea and ${ }^{2}$ Department of Organic and Polymeric Materials, Tokyo Institute of Technology, Tokyo, Japan ${ }^{3}$ These authors contributed equally to this work.

Correspondence: Professor T Michinobu, Department of Organic and Polymeric Materials, Tokyo Institute of Technology, 2-12-1-S8-24 Ookayama, Meguro-ku, Tokyo 152-8552, Japan. E-mail: michinobu.t.aa@m.titech.ac.jp

or Professor M Ree, Department of Chemistry, Division of Advanced Materials Science, Pohang Accelerator Laboratory, Polymer Research Institute, and BK School of Molecular Science, Pohang University of Science and Technology, Pohang 790-784, Republic of Korea.

E-mail: ree@postech.edu
}

Received 17 August 2015; revised 25 September 2015; accepted 6 October 2015 


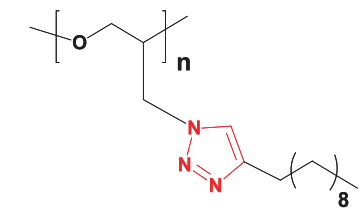

PG-Triazole- $C_{10}$

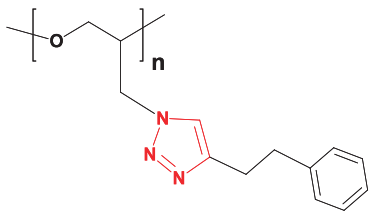

PG-Triazole- $\mathrm{C}_{2} \mathrm{P}$

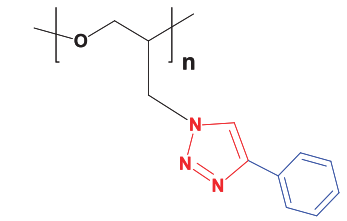

PG-Triazole-P

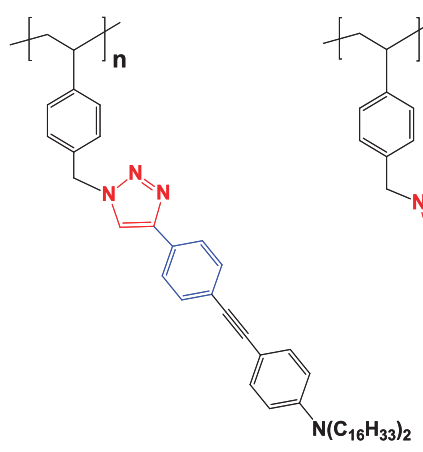

PS-Triazole-PEP

PS-Triazole-PTCNE

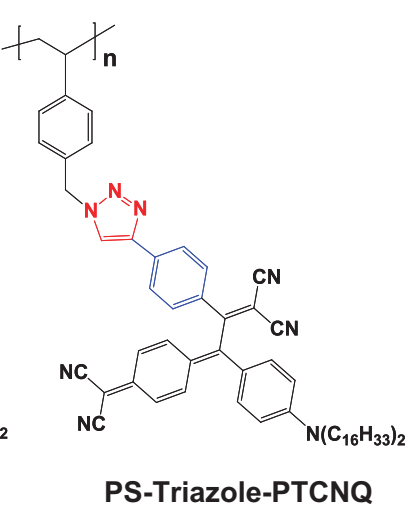

Figure 1 Chemical structures of the brush polymers bearing triazole moieties generated by azide-alkyne click chemistry reactions.

both electron-donor and -acceptor units as parts of the backbone and/or side groups have been reported. ${ }^{18-20,26-29}$ In particular, the majority of the nonconjugated polymers have been synthesized with carbazole, triphenylamine, fluorine and their derivatives. ${ }^{18-20,26-29}$ Moreover, they are known to mainly exhibit $p$-type electrical memory characteristics. In contrast, $n$-type memory polymers have rarely been reported. ${ }^{20,30}$ Therefore, research on functional polymers with highperformance electrical memory characteristics remains in the early developmental stages.

This study presents the first attempt at developing highperformance electrical memory polymers using triazole ring formation based on azide-alkyne click chemistry in a positive way. A series of brush polyglycidyl (PG) derivatives bearing the triazole moiety in their bristle was synthesized: $\operatorname{poly}(\operatorname{oxy}(4-(n$-decyl $)-1,2,3$-triazol-1-yl $)$ methyl)ethylene) (PG-Triazole- $\left.\mathrm{C}_{10}\right)$, poly(oxy(4-(phenyl-1,2-ethyl)1,2,3-triazol-1-yl)methyl)ethylene) (PG-Triazole- $\left.\mathrm{C}_{2} \mathrm{P}\right)$, and poly (oxy(4-(phenyl)-1,2,3-triazol-1-yl)methyl)ethylene) (PG-Triazole-P) (Figure 1). Another series of brush polystyrenyl (PS) derivatives bearing the triazole moiety in their bristle was prepared: poly(1-(4((4-(4-((4-(dihexadecylamino)-phenyl)ethynyl)phenyl)-1,2,3-triazol-1yl)methyl)phenyl)ethylene) (PS-Triazole-PEP), poly(1-(4-((4-(4(1,1,4,4-tetracyano-3-(4-(dihexadecylamino)phenyl)buta-1,3-dien-2-yl) phenyl)-1,2,3-triazol-1-yl)-methyl)phenyl)-ethylene) (PS-TriazolePTCNE), and poly(1-(4-((4-(4-(1,1-dicyano-3-(4-(dicyanomethylene) cyclohexa-2,5-dien-1-ylidene)-3-(4-(dihexadecylamino)phenyl)prop-1en-2-yl)-phenyl)-1,2,3-triazol-1-yl)methyl)phenyl)ethylene) (PS-Triazole-PTCNQ) (Figure 1). These brush polymers were observed to be soluble in organic solvents and therefore could be easily processed as nanoscale thin films via conventional solution casting processes. Their thin-film morphologies and properties, including their molecular orbital characteristics, were investigated. Devices with aluminum top and bottom electrodes were fabricated with thin films of the brush polymers with thicknesses as high as $65 \mathrm{~nm}$ to evaluate their electrical memory performance. Interestingly, the PG-Triazole-P, PS-TriazolePEP, PS-Triazole-PTCNE and PS-Triazole-PTCNQ film layers in the devices demonstrated excellent unipolar nonvolatile memory behaviors, with low power consumption. Their memory types could be further tuned to $p$ - or $n$-type, depending on the substituent(s) of the triazole moiety. Furthermore, these devices were confirmed to function properly after storage in ambient air for 1 year, exhibiting high stability and reliability. Such nonvolatile memory characteristics were, however, observed to be limited for films up to $30 \mathrm{~nm}$ thickness. Unlike these brush polymers, the PG-Triazole- $\mathrm{C}_{10}$ and PG-Triazole- $\mathrm{C}_{2} \mathrm{P}$ devices exhibited no electrical memory behaviors. Overall, these exciting electrical characteristics were examined with respect to the chemical nature (chemical composition, inductive effect, resonance effect and molecular orbitals) and nanoscale thin-film morphology of the triazole-containing brush polymers. For the observed memory behaviors, possible electrical switching mechanisms are further discussed.

\section{MATERIALS AND METHODS}

\section{Synthesis}

All reagents were purchased from Aldrich (St Louis, MO, USA), Kanto (Tokyo, Japan), Tokyo Kasei (Tokyo, Japan) or Wako Chemical (Osaka, Japan) and were used as received. A series of brush polyepichlorohydrin derivatives bearing triazole moieties was prepared in a three-step procedure as follows. In the firststep, poly(epichlorohydrin) (PECH) was synthesized according to the method reported previously..$^{31}$ Epichlorohydrin $(40 \mathrm{ml}, 512 \mathrm{mmol})$ was cooled to $-5^{\circ} \mathrm{C}$ under a nitrogen atmosphere. Triphenylcarbenium hexafluorophosphate $(0.1 \mathrm{~g}$, $0.256 \mathrm{mmol}$ ) was dissolved in $\mathrm{CH}_{2} \mathrm{Cl}_{2}$ and slowly added to the reaction mixture. The solution was stirred at room temperature for $48 \mathrm{~h}$. The crude polymer was purified by precipitation from $\mathrm{CH}_{2} \mathrm{Cl}_{2}$ into methanol several times and finally dried in vacuo at $40^{\circ} \mathrm{C}$ for $12 \mathrm{~h}$, giving a colorless viscous liquid. Yield: $65 \%$. The $\mathrm{PECH}$ product was identified in deuterated chloroform $\left(\mathrm{CDCl}_{3}\right)$ by nuclear magnetic resonance (NMR) spectroscopy analysis with proton $\left({ }^{1} \mathrm{H}\right)$ and carbon $\left({ }^{13} \mathrm{C}\right)$ probes using a Bruker spectrometer (model AV300 FT-NMR, Bruker, Rheinstetten, BW, Germany). ${ }^{1} \mathrm{H}$ NMR (300 MHz, $\mathrm{CDCl}_{3}, \delta$ (p.p.m.)): 3.89-3.49 (br, 5H, OCH, $\mathrm{OCH}_{2}, \mathrm{CH}_{2} \mathrm{Cl}$ ); ${ }^{13} \mathrm{C} \mathrm{NMR}\left(75 \mathrm{MHz}, \mathrm{CDCl}_{3}, \delta\right.$ (p.p.m.)): 79.70, 70.32, 44.31.

The molecular weight of the obtained $\mathrm{PECH}$ polymer was determined by gel permeation chromatography (model PL-GPC 210, Polymer Labs, Amherst, MA, USA) on an instrument equipped with a set of gel columns (two columns of PL Gel Mixed-C). The system was equilibrated at $25^{\circ} \mathrm{C}$ in anhydrous $\mathrm{CHCl}_{3}$ (which was used as the polymer solvent and eluent at a flow rate of $0.8 \mathrm{ml} \mathrm{min}^{-1}$ ) and calibrated with polystyrene standards. The PECH polymer 
was observed to have a number-average molecular weight $\overline{M_{n}}$ of 22700 and a polydispersity index $\left(\overline{M_{w}} / \overline{M_{n}}\right.$, where $\overline{M_{w}}$ is the weight-average molecular weight) of 1.68 .

In the second step, the PECH polymer was converted into poly(glycidyl azide) (PGA). PECH (1.7 g, $1.72 \times 10^{-2} \mathrm{~mol}$ chloro group) was dissolved in $\mathrm{N}$, $\mathrm{N}$-dimethylformamide (DMF) at $60-70^{\circ} \mathrm{C}$ and then cooled to room temperature. Sodium azide $\left(\mathrm{NaN}_{3}, 11.15 \mathrm{~g}, 0.1715 \mathrm{~mol}\right)$ was added to the polymer solution, which was subsequently stirred at $95^{\circ} \mathrm{C}$ for $24 \mathrm{~h}$. After the solution was stirred for $24 \mathrm{~h}$, the crude product was filtered to remove the remaining solid sodium azide and then evaporated under reduced pressure. The crude product was dissolved in $\mathrm{CHCl}_{3}(150 \mathrm{ml})$ and washed with brine $(50 \mathrm{ml})$ three times. The organic layers were then dried over magnesium sulfate $\left(\mathrm{MgSO}_{4}\right)$, filtered and evaporated under reduced pressure. The product was further dried in vacuo at $40^{\circ} \mathrm{C}$ for $24 \mathrm{~h}$. Yield: $95 \%$. The PGA product was identified by NMR analysis. Infrared (IR) spectroscopy analysis was further carried out using an ATI Mattson IR spectrometer (model Research Series, Mattson Instrument, Madison, WI, USA) and a JASCO spectrometer (model FT/IR 4100, JASCO, Easton, MD, USA). ${ }^{1} \mathrm{H}$ NMR $\left(300 \mathrm{MHz}, \mathrm{CDCl}_{3}, \delta\right.$ (p.p.m.)): 3.791-3.353 (br, $5 \mathrm{H}, \mathrm{OCH}, \mathrm{OCH}_{2}, \mathrm{CH}_{2} \mathrm{~N}_{3}$ ). IR (film, $\nu\left(\mathrm{cm}^{-1}\right)$ ): 2917, 2877, 2102, 1625, 1442, 1344, 1282, 1128 (Supplementary Figure S1a).

In the final step, PGA $\left(0.150 \mathrm{~g}, 1.51 \times 10^{-3} \mathrm{~mol}\right.$ azido group $)$, 1-dodecyne $\left(0.355 \mathrm{ml}, 1.66 \times 10^{-3} \mathrm{~mol}\right)$ and $\mathrm{Cu}(\mathrm{I}) \mathrm{Br}\left(5 \mathrm{~mol} \%, 1.14 \times 10^{-2} \mathrm{~g}\right.$, $\left.7.97 \times 10^{-2} \mathrm{~mol}\right)$ were dissolved in DMF $(30.27 \mathrm{ml})$. A reaction mixture was added to a dried Schlenk flask, followed by degassing via three freeze-pumpthaw cycles. The solution was stirred at $55^{\circ} \mathrm{C}$ for $48 \mathrm{~h}$ and then cooled to room temperature. The solvent was removed by vacuum distillation. The concentrated polymer solution was passed through activated alumina columns to remove the $\mathrm{Cu}(\mathrm{I}) \mathrm{Br}$ catalyst residue. After filtration, the filtrate was evaporated under reduced pressure. The concentrated crude polymer was further purified by precipitation from DMF into cold ether several times and dried in vacuo at $40^{\circ} \mathrm{C}$ for $24 \mathrm{~h}$, giving the target polymer product PG-Triazole$\mathrm{C}_{10}$ as a white solid. Yield: $79 \% .{ }^{1} \mathrm{H}$ NMR $\left(300 \mathrm{MHz}, \mathrm{CDCl}_{3}, \delta\right.$ (p.p.m.)): 7.608-7.351 (br, $1 \mathrm{H}$, triazole), $4.369-3.328\left(\mathrm{br}, 5 \mathrm{H}, \mathrm{OCH}, \mathrm{OCH}_{2},-\mathrm{CH}_{2^{-}}\right.$ triazole), 2.646 (br, $2 \mathrm{H}$, triazole- $\left.\mathrm{CH}_{2}\right), 1.601$ (br, $2 \mathrm{H},-\mathrm{CH}_{2} \mathrm{CH}_{2^{-}}$in the brush), 1.242 (br, $\left.14 \mathrm{H},-\mathrm{CH}_{2} \mathrm{CH}_{2}\left(\mathrm{CH}_{2}\right)_{6} \mathrm{CH}_{3}\right), 0.866$ (br, 3H, $\left.-\mathrm{CH}_{2}\left(\mathrm{CH}_{2}\right)_{7} \mathrm{CH}_{3}\right)$ (Supplementary Figure S2a). IR (film, $\nu\left(\mathrm{cm}^{-1}\right)$ ): 3129, 3068, 2919, 2850, 1691, 1550, 1463, 1374, 1342, 1216, 1116, 1047 (Supplementary Figure S1b).

In a similar manner, PG-Triazole- $\mathrm{C}_{2} \mathrm{P}$ was synthesized in DMF $(30.27 \mathrm{ml})$ from the click reaction of PGA $\left(0.150 \mathrm{~g}, 1.51 \times 10^{-3} \mathrm{~mol}\right.$ azido group $)$ and 4-phenyl-1-butyne $\left(0.206 \mathrm{~g}, 1.59 \times 10^{-3} \mathrm{~mol}\right)$. The target polymer product was obtained as a pale-green solid. Yield: $72 \% .{ }^{1} \mathrm{H}$ NMR $\left(300 \mathrm{MHz}, \mathrm{CDCl}_{3}\right.$, $\delta$ (p.p.m.)): 7.564-7.332 (br, $1 \mathrm{H}$, triazole), 7.182-7.109 (br, 5H, aromatic proton), 4.545-3.112 (br, 5H, OCH, $\mathrm{OCH}_{2},-\mathrm{CH}_{2}$-triazole), 2.957-2.713 (br, $4 \mathrm{H}$, triazole- $\mathrm{CH}_{2} \mathrm{CH}_{2}-\mathrm{C}_{6} \mathrm{H}_{5}$ ) (Supplementary Figure S2b). IR (film, $\nu\left(\mathrm{cm}^{-1}\right)$ ): 3133 3081, 3060, 2919, 2852, 1602, 1550, 1496, 1454, 1338, 1218, 1114, 1047 (Supplementary Figure S1c).

In addition, PG-Triazole-P was prepared in DMF $(30.27 \mathrm{ml})$ from PGA $\left(0.150 \mathrm{~g}, \quad 1.51 \times 10^{-3} \mathrm{~mol}\right.$ azido group $)$ and phenylacetylene $(0.17 \mathrm{~g}$, $\left.1.66 \times 10^{-3} \mathrm{~mol}\right)$. The polymer was obtained as a pale-green solid. Yield: 74\%. ${ }^{1} \mathrm{H}$ NMR (300 MHz, $\mathrm{CDCl}_{3}, \delta$ (p.p.m.)): 8.197-7.479 (br, 3H, triazole, aromatic proton), 7.358-6.937 (br, $3 \mathrm{H}$, aromatic proton), 4.644-3.056 (br, $5 \mathrm{H}$, $\mathrm{OCH}, \mathrm{OCH}_{2},-\mathrm{CH}_{2}$-triazole) (Supplementary Figure S2c). IR (film, $\nu\left(\mathrm{cm}^{-1}\right)$ ): 3131, 3066, 2919, 2850, 1550, 1463, 1376, 1315, 1218, 1116, 1047 (Supplementary Figure S2d).

Another series of brush polystyrene derivatives bearing triazole moieties was prepared according to a synthetic method reported in the literature. ${ }^{8}$ In the synthesis, poly(4-azidomethylstyrene) (PS) with $\overline{M_{n}}=11500$ and polydispersity index $=1.75$ was prepared and used. PS-Triazole-PEP was synthesized as follows. To a solution of PS $\left(3.10 \times 10^{-2} \mathrm{~g}, 2.00 \times 10^{-4} \mathrm{~mol}\right.$ azido group $)$ in DMF (8 ml), 4-((4-ethynylphenyl)ethynyl)- $N, N$-dihexadecylaniline $(0.130 \mathrm{~g}$, $0.20 \mathrm{mmol})$, sodium ascorbate $\left(3.90 \times 10^{-3} \mathrm{~g}, 1.20 \times 10^{-5} \mathrm{~mol}\right)$ and copper (II) sulfate pentahydrate $\left(2.30 \times 10^{-3} \mathrm{~g}, 9.80 \times 10^{-6} \mathrm{~mol}\right)$ were added under argon. The mixture was stirred at $20^{\circ} \mathrm{C}$ for $24 \mathrm{~h}$, yielding a yellow precipitate. The precipitate was filtered and washed with DMF, methanol and water, affording the target product PS-Triazole-PEP as a yellow solid. The target product was further dried in vacuo at room temperature for $48 \mathrm{~h}$. Yield: $98 \%$. ${ }^{1} \mathrm{H}$ NMR $\left(300 \mathrm{MHz}, \mathrm{CDCl}_{3}, \delta\right.$ (p.p.m.)): 7.74 (br, 5H, aromatic proton, triazole), $7.30(\mathrm{~d}, J=12.6 \mathrm{~Hz}, 4 \mathrm{H}$, aromatic proton), $6.75(\mathrm{br}, 2 \mathrm{H}$, aromatic proton), 6.48 (br, $2 \mathrm{H}$, aromatic proton), $5.47\left(\mathrm{~s}, 2 \mathrm{H},-\mathrm{CH}_{2}\right.$-triazole), 3.19 (br, $\left.4 \mathrm{H}, \mathrm{NCH}_{2}\right), 1.57$ (m, 7H, - $\left.\mathrm{CH}_{2} \mathrm{CHPh}-, \mathrm{NCH}_{2} \mathrm{CH}_{2}\right), 1.25\left(\mathrm{~s}, 52 \mathrm{H},-\mathrm{CH}_{2}\right.$ ), $0.86\left(\mathrm{~m}, 6 \mathrm{H}, \mathrm{CH}_{3}\right)$ (Supplementary Figure S3a). IR (film, $\nu\left(\mathrm{cm}^{-1}\right)$ ): 2920.7, 2851.2, 2207.1, 1602.6, 1518.7, 1458.9, 1401.0, 1366.3, 1275.7, 1261.2, 1225.5, $1189.9,1136.8,1071.3,1044.3,1018.2,971.9,842.7,811.9,751.1,727.0,712.6$, 605.5, 581.4, 539.0 (Supplementary Figure S4a).

A fraction of PS-Triazole-PEP was further converted into PS-TriazolePTCNE. To a solution of PS-Triazole-PEP $\left(2.45 \times 10^{-2} \mathrm{~g}, 2.95 \times 10^{-5} \mathrm{~mol}\right.$ acetylenyl group) in $\mathrm{CHCl}_{3}(0.3 \mathrm{ml})$, a tetracyanoethylene (TCNE) solution in 1,2-dichloroethane $(0.163 \mathrm{M}, 0.18 \mathrm{ml})$ was added to the polymer solution under ambient air. The mixture was stirred at $20^{\circ} \mathrm{C}$ for $1 \mathrm{~h}$. The solution was evaporated to afford the target product. Yield: $>98 \%$. ${ }^{1} \mathrm{H}$ NMR $(300 \mathrm{MHz}$, $\mathrm{CDCl}_{3}, \delta$ (p.p.m.)): 7.98 (s, $1 \mathrm{H}$, triazole), 7.69 (br, $8 \mathrm{H}$, aromatic proton), 6.68 (br, $4 \mathrm{H}$, aromatic proton), $5.48\left(\mathrm{~s}, 2 \mathrm{H},-\mathrm{CH}_{2}\right.$-triazole), $3.34\left(\mathrm{~m}, 4 \mathrm{H}, \mathrm{NCH}_{2}\right)$, 1.59 (s, 7H, - $\left.\mathrm{CH}_{2} \mathrm{CHPh}-, \mathrm{NCH}_{2} \mathrm{CH}_{2}\right), 1.24\left(\mathrm{~s}, 52 \mathrm{H},-\mathrm{CH}_{2^{-}}\right), 0.86\left(\mathrm{~m}, 6 \mathrm{H}, \mathrm{CH}_{3}\right)$ (Supplementary Figure S3b). IR (film, $\nu\left(\mathrm{cm}^{-1}\right)$ ): 2921.6, 2851.2, 2213.9, $1601.6,1537.0,1484.9,1452.1,1415.5,1314.1,1295.9,1267.0,1210.1$, $1180.2,1073.1,1044.3,1018.2,971.9,847.6,818.6,796.5,774.3,728.0$, 712.6, 685.6, 648.9, 633.5, 601.7, 579.5, 560.2, 548.6, 526.5 (Supplementary Figure S4b). Elemental analysis calcd. for $\left(\mathrm{C}_{63} \mathrm{H}_{84} \mathrm{~N}_{8}\right)_{\mathrm{n}}$ : C 79.37, $\mathrm{H}$ 8.88, N 11.75\%; found: C 79.56, H 9.27, N 11.17\%

Another fraction of PS-Triazole-PEP was converted into PS-TriazolePTCNQ. To a solution of PS-Triazole-PEP $\left(2.10 \times 10^{-2} \mathrm{~g}, 2.54 \times 10^{-5} \mathrm{~mol}\right.$ acetylenyl group) in $O$-dichlorobenzene, a 7,7,8,8-tetracyanoquinodimethane (TCNQ) solution in 1,2-dichloroethane $(7.0 \mathrm{~mm}, 3.6 \mathrm{ml})$ was added to the polymer solution under a nitrogen atmosphere. The resulting mixture was stirred at $160^{\circ} \mathrm{C}$ for $24 \mathrm{~h}$. The solution was evaporated to afford the target product. Yield: $>98 \% .{ }^{1} \mathrm{H}$ NMR $\left(300 \mathrm{MHz}, \mathrm{CDCl}_{3}, \delta\right.$ (p.p.m.)): $8.00-7.70$ (s, $1 \mathrm{H}$, triazole), $7.50-7.37(\mathrm{br}, 4 \mathrm{H}$, aromatic proton), 7.07-6.72 (br, $4 \mathrm{H}$, aromatic proton), $6.70-6.42(\mathrm{br}, 6 \mathrm{H}$, aromatic proton), $5.50-5.15(\mathrm{br}, 2 \mathrm{H}$, - $\mathrm{CH}_{2}$-triazole), $3.33\left(\mathrm{~m}, 4 \mathrm{H}, \mathrm{NCH}_{2}\right), 1.60\left(\mathrm{~s}, 7 \mathrm{H},-\mathrm{CH}_{2} \mathrm{CHPh}-, \mathrm{NCH}_{2} \mathrm{CH}_{2}\right)$, $1.26\left(\mathrm{~s}, 52 \mathrm{H},-\mathrm{CH}_{2^{-}}\right), 0.87\left(\mathrm{~m}, 6 \mathrm{H}, \mathrm{CH}_{3}\right)$ (Supplementary Figure $\mathrm{S} 3 \mathrm{c}$ ). IR (film, $\nu\left(\mathrm{cm}^{-1}\right)$ ): 2921.6, 2851.2, 2202.3, 1607.4, 1579.4, 1518.7, 1457.9, $1397.1,1346.1,1276.7,1261.2,1173.5,1072.2,1043.3,1017.3,971.9,908.3$, 885.2, 822.5, 751.1, $711.6, \quad 672.1, \quad 635.4, \quad 604.6, \quad 580.5, \quad 553.5, \quad 537.1$ (Supplementary Figure S4c). Elemental analysis calcd. for $\left(\mathrm{C}_{69} \mathrm{H}_{88} \mathrm{~N}_{8}\right)_{\mathrm{n}}$ : C $80.50, \mathrm{H} 8.62, \mathrm{~N} 10.88 \%$; found: C $81.07, \mathrm{H} 8.93, \mathrm{~N} 10.00 \%$.

\section{Measurements}

The thermal properties were determined by thermogravimetric analysis and differential scanning calorimetric (DSC) analysis using a ramp rate of $10.0^{\circ} \mathrm{C} \mathrm{min}{ }^{-1}$ and with the samples under a nitrogen atmosphere. Thermogravimetric analysis and DSC measurements were carried out using a Seiko instrument (model SII TG/DTA 6200, Seiko, Tokyo, Japan) and a Seiko calorimeter (model SII DSC 6220), respectively. Ultraviolet-visible (UV-vis) spectroscopy measurements were conducted using a Scinco spectrometer (model S-3100, Scinco, Seoul, Korea). Cyclic voltammetry measurements were conducted at $20^{\circ} \mathrm{C}$ under argon with a scan rate of $100 \mathrm{mV} \mathrm{s}^{-1}$ and with either tetrahydrofuran, $\mathrm{CH}_{2} \mathrm{Cl}_{2}$ or $\mathrm{O}$-dichlorobenzene containing $0.1 \mathrm{M}\left(n \mathrm{C}_{4} \mathrm{H}_{9}\right)$ ${ }_{4} \mathrm{NClO}_{4}$ as the electrolyte using an electrochemical workstation (IM6ex impedance analyzer, ZAHNER-Elektrik, Kronach, Germany) with a threeelectrode cell (a working electrode (platinum wire of $1.6 \mathrm{~mm}$ diameter or glassy carbon disk of $2.0 \mathrm{~mm}$ diameter), a reference electrode $\left(\mathrm{Ag} / \mathrm{Ag}^{+} / \mathrm{CH}_{3} \mathrm{CN} /\right.$ $\left.\left(n \mathrm{C}_{4} \mathrm{H}_{9}\right)_{4} \mathrm{NClO}_{4}\right)$ and a Pt auxiliary electrode); in the measurements, a ferrocene/ferricinium $\left(F_{\mathrm{c}} / F_{\mathrm{c}}{ }^{+}\right)$couple was used as an internal standard. Synchrotron grazing incidence X-ray scattering (GIXS) measurements were conducted for nanoscale thin films of the polymers, which were spin-coated onto silicon ( $\mathrm{Si}$ ) substrates and dried in vacuo for $24 \mathrm{~h}$. For the nanoscale film preparation, each polymer was dissolved in $\mathrm{CHCl}_{3}$ at a concentration of $0.5 \mathrm{wt} \%$ and then filtered through polytetrafluoroethylene membrane microfilters with a pore size of $0.2 \mu \mathrm{m}$ at room temperature before use. The obtained films were measured using spectroscopic ellipsometry (model M2000, Woollam, Lincoln, NE, USA). GIXS measurements were carried out with an incident angle $\alpha_{\mathrm{i}}$ of $0.132-0.154^{\circ}$ using a two-dimensional (2D) chargecoupled detector (MAR USA, Evanston, IL, USA) at the 3C beamline of the 
Pohang Accelerator Laboratory in accordance with the method reported in the literature. ${ }^{32,33} \mathrm{X}$-ray radiation sources with a wavelength $\lambda$ of 0.1117 and $0.1166 \mathrm{~nm}$ were used. The sample-to-detector distances were 229.0 and $233.9 \mathrm{~mm}$. In addition, synchrotron X-ray reflectivity (XR) analysis was conducted in $\theta-2 \theta$ scanning mode at the $3 \mathrm{D}$ beamline $\mathrm{b}^{34-36}$ of Pohang Accelerator Laboratory. An X-ray radiation source $(\lambda=0.1240 \mathrm{~nm})$ was used, and the beam size at the sample position was $0.1 \times 2.0 \mathrm{~mm}^{2}$. The measured data were subjected to geometrical correction and background subtraction using a procedure described in the literature. ${ }^{34}$

\section{Device fabrication and analysis}

Al strips (300-nm thick) with widths of 0.1 and $0.2 \mathrm{~mm}$ were deposited as bottom electrodes onto Si substrates with thermally grown oxide layers through a shadow mask by electron-beam sputtering. The polymer solutions were spincast onto the $\mathrm{Al}$ bottom electrodes and dried in vacuo at room temperature for $24 \mathrm{~h}$. The obtained films were measured by spectroscopic ellipsometry to be $10-50-\mathrm{nm}$ thick. Al strips (300-nm thick) were subsequently deposited as top electrodes with widths of 0.1 and $0.2 \mathrm{~mm}$ onto the polymer film layers through a shadow mask by thermal evaporation under vacuum. $I-V$ analyses were conducted under ambient air at room temperature using a semiconductor analyzer (model 4200, Keithley, Cleveland, OH, USA).

\section{RESULTS AND DISCUSSION}

Two series of brush polymers bearing a single triazole moiety in the bristle per repeat unit were successfully synthesized via the azide-alkyne click chemistry reaction, as described in the experimental section: $\mathrm{PG}$-Triazole- $\mathrm{C}_{10}$, PG-Triazole- $\mathrm{C}_{2} \mathrm{P}$, PG-Triazole-P, PS-Triazole-PEP, PS-Triazole-PTCNE, and PS-Triazole-PTCNQ. All click chemistry polymer products were observed to be soluble in organic solvents, including chloroform $\left(\mathrm{CHCl}_{3}\right)$, methylene chloride $\left(\mathrm{CH}_{2} \mathrm{Cl}_{2}\right)$, tetrahydrofuran, $\mathrm{O}$-dichlorobenzene and DMF, allowing easy fabrication into nanoscale thin films via conventional solution casting processes.

Figure 2 presents the thermal properties of the polymers. PG-Triazole-P is thermally stable up to $280^{\circ} \mathrm{C}\left(=T_{\mathrm{d}}\right.$, the onset temperature of degradation; Figure 2a). In comparison, the other
PG-based polymers exhibit relatively higher thermal stabilities $\left(T_{\mathrm{d}}=320^{\circ} \mathrm{C}\right)$. PS-Triazole-PEP, however, exhibits a relatively lower thermal stability $\left(T_{\mathrm{d}}=236^{\circ} \mathrm{C}\right.$; Figure $\left.2 \mathrm{~b}\right)$. This low stability might originate from the presence of an unsaturated acetylenyl linker in the bristle. This low thermal stability could be somewhat improved to $236-294{ }^{\circ} \mathrm{C}$ through the incorporation of TCNE and TCNQ into the acetylenyl linker. In the DSC runs (Figure 2c), PG-Triazole- $\mathrm{C}_{10}$ interestingly exhibits a glass-transition temperature $T_{\mathrm{g}}$ of $43^{\circ} \mathrm{C}$ and a melting transition $T_{\mathrm{m}}$ at $123^{\circ} \mathrm{C}$, indicating that this polymer is crystalline. Given the amorphous nature of $\mathrm{PECH}$, the observed crystalline characteristic is attributable to the lateral ordering of $n$-decyl groups in the bristles. However, PG-Triazole- $\mathrm{C}_{2} \mathrm{P}$ exhibits only a glass transition, at approximately $45^{\circ} \mathrm{C}$. PG-Triazole-P also exhibits only a $T_{\mathrm{g}}$ at $102^{\circ} \mathrm{C}$. These results indicate that both PG-Triazole- $\mathrm{C}_{2} \mathrm{P}$ and $\mathrm{PG}$-Triazole-P are amorphous rather than crystalline. In contrast, the PS-based polymers exhibit no clear phase transitions, as shown in Figure $2 \mathrm{~d}$. Instead, only a very weak, broad glass transition is discernible at approximately $113^{\circ} \mathrm{C}$ for PS-Triazole-PEP, approximately $105^{\circ} \mathrm{C}$ for PS-Triazole-PTCNE and approximately $125^{\circ} \mathrm{C}$ for PS-Triazole-PTCNQ.

The polymers were further analyzed by UV-vis spectroscopy and cyclic voltammetry. From the UV-vis spectra in Figure 3, the band gaps were determined to be $4.83 \mathrm{eV}$ for $\mathrm{PG}$-Triazole- $\mathrm{C}_{10}, 4.49 \mathrm{eV}$ for PG-Triazole- $C_{2} P, \quad 4.29 \mathrm{eV}$ for PG-Triazole-P, $3.09 \mathrm{eV}$ for PS-Triazole-PEP, $2.02 \mathrm{eV}$ for PS-Triazole-PTCNE and $1.37 \mathrm{eV}$ for PS-Triazole-PTCNQ. The oxidation half-wave potentials $\left(E_{\mathrm{Ox}}\right)$ vs $F_{\mathrm{C}} / F_{\mathrm{c}}{ }^{+}$were determined to be $0.35 \mathrm{~V}$ for PG-Triazole- $\mathrm{C}_{10}, 0.28 \mathrm{~V}$ for PG-Triazole- $\mathrm{C}_{2} \mathrm{P}, 0.01 \mathrm{~V}$ for PG-Triazole-P, $0.25 \mathrm{~V}$ for PS-TriazolePEP, $0.80 \mathrm{~V}$ for PS-Triazole-PTCNE and $0.27 \mathrm{~V}$ for PS-TriazolePTCNQ (Figure 4). Assuming that the highest occupied molecular orbital (HOMO) level for the $F_{\mathrm{c}} / F_{\mathrm{c}}{ }^{+}$standard is $-4.80 \mathrm{eV}$ with respect to the zero vacuum level, on the basis of the measured $E_{\mathrm{Ox}}$ data, the HOMO levels were estimated to be $-5.15 \mathrm{eV}$ for PG-Triazole- $\mathrm{C}_{10}$, $-5.08 \mathrm{eV}$ for PG-Triazole- $\mathrm{C}_{2} \mathrm{P},-4.81 \mathrm{eV}$ for PG-Triazole-P, $-5.05 \mathrm{eV}$
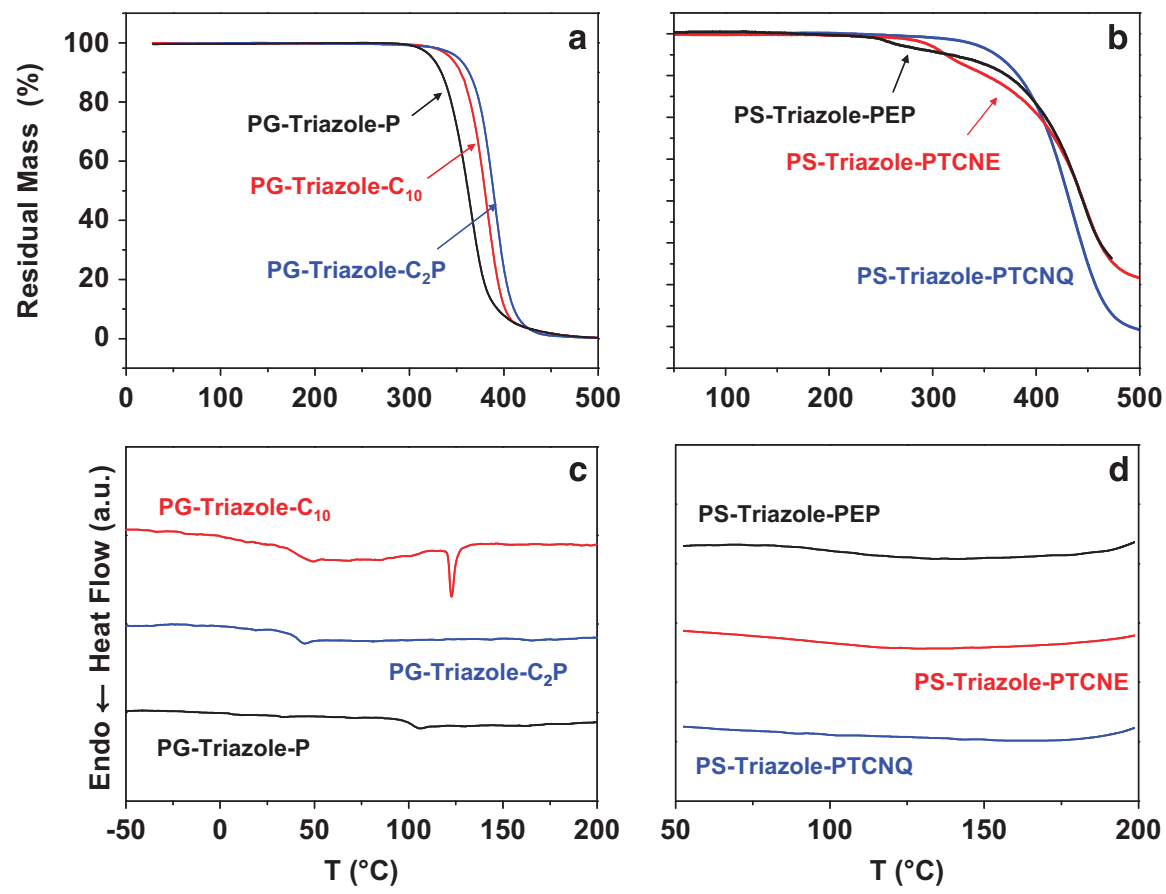

Figure 2 (a, b) Thermogravimetric analysis and (c, d) DSC thermograms of triazole-containing brush polymers; the scans were performed at a rate of $10.0^{\circ} \mathrm{C} \mathrm{min}^{-1}$ with the samples under a nitrogen atmosphere. 

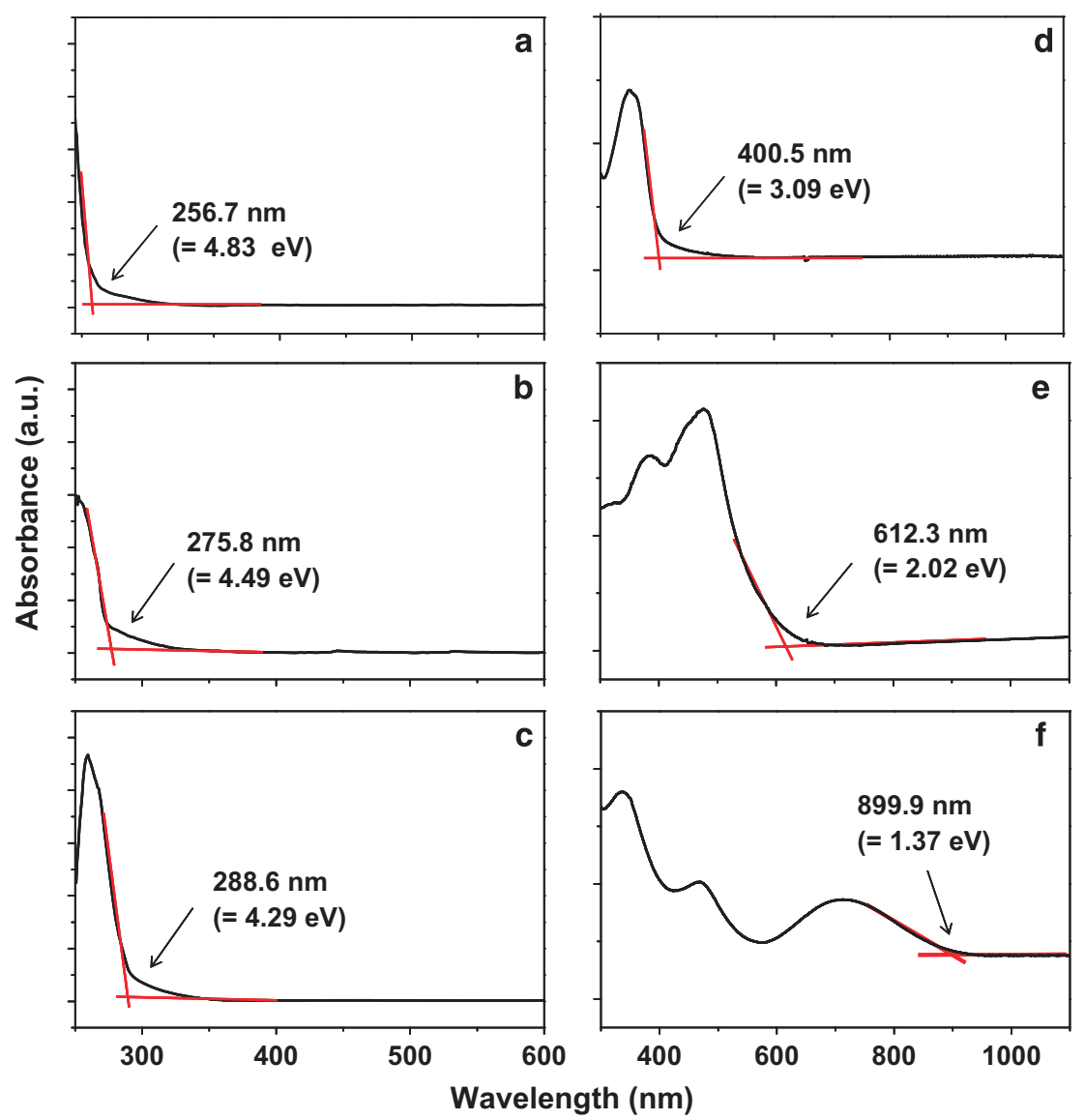

Figure 3 UV-vis spectra of triazole-containing brush polymers: (a) PG-Triazole- $C_{10}$; (b) PG-Triazole- $C_{2} P$; (c) PG-Triazole-P; (d) PS-Triazole-PEP; (e) PS-Triazole-PTCNE; (f) PS-Triazole-PTCNQ. The spectra of the PG-based polymers were collected for thin films coated onto quartz substrates, whereas those of the PS-based polymers were collected with the samples dissolved in $\mathrm{CHCl}_{3}$.

for PS-Triazole-PEP, $-5.60 \mathrm{eV}$ for PS-Triazole-PTCNE and $-5.07 \mathrm{eV}$ for PS-Triazole-PTCNQ. On the basis of the band-gap and HOMO data, the lowest unoccupied molecular orbital (LUMO) levels were determined to be $-0.32 \mathrm{eV}$ for PG-Triazole- $\mathrm{C}_{10},-0.59 \mathrm{eV}$ for PG-Triazole- $\mathrm{C}_{2} \mathrm{P}, \quad-0.52 \mathrm{eV}$ for $\mathrm{PG}$-Triazole-P, $-1.96 \mathrm{eV}$ for PS-Triazole-PEP, $-3.58 \mathrm{eV}$ for PS-Triazole-PTCNE and $-3.70 \mathrm{eV}$ for PS-Triazole-PTCNQ.

The morphological structures of the polymers in nanoscale thin films (10-65-nm thick) were investigated by synchrotron GIXS and XR analyses. As shown in Figure 5a, the two-dimensional (2D) GIXS pattern of the PG-Triazole- $\mathrm{C}_{10}$ contains features, again confirming that the polymer is crystalline. A series of scattering spots appears at $1.91^{\circ}, 3.77^{\circ}, 5.66^{\circ}$ and $7.59^{\circ}$ along the $\alpha_{\mathrm{f}}$ direction at $2 \theta_{\mathrm{f}}=0^{\circ}$; here, $\alpha_{\mathrm{f}}$ and $2 \theta_{\mathrm{f}}$ are the out-of-plane and in-plane exit angles, respectively, of the out-going X-ray beam. Their relative scattering vector lengths from the specular reflection position are 1,2, 3 and 4, respectively, indicating that they are the first- to fourth-order scattering spots. These spots were not discernible along the $2 \theta_{\mathrm{f}}$ direction at $\alpha_{\mathrm{f}}=0^{\circ}$. Collectively, these scattering characteristics indicate the presence of a horizontally oriented lamellar structure in the nanoscale thin film. From such scattering spots, the horizontal lamellar structure was determined to have a long period $L$ of $3.45 \mathrm{~nm}$. The out-of-plane scattering profile (which was extracted along the $\alpha_{\mathrm{f}}$ direction at $2 \theta_{\mathrm{f}}=0^{\circ}$ ) was successfully fitted using the GIXS formula derived from a lamellar structure model with three sublayers (Figures $6 a$ and d); the GIXS formula derivation has been reported previously. ${ }^{6}$
The second-order orientation factor $O_{\mathrm{s}}$ of the lamellar structure was further determined by analysis of the azimuthal scattering profile extracted at $1.91^{\circ}$ from the 2D GIXS pattern (Figure $6 \mathrm{~b}$ ). In addition, a scattering arc appears at $2 \theta_{\mathrm{f}}=13.48^{\circ}(0.47 \mathrm{~nm} d$-spacing $)$. Given the chemical structure of PG-Triazole- $\mathrm{C}_{10}$ and its horizontal lamellar structure in the thin film, the scattering arc originates from the mean interdistance of the alkyl end groups in the ordered bristles, which are preferentially aligned in the direction normal to the film plane (or lamellar plane). The orientation of the alkyl end groups in the ordered state was estimated via analysis of the azimuthal scattering profile extracted at $13.48^{\circ}$ from the 2D GIXS pattern (Figure 6c). These GIXS analysis results indicate that the horizontal lamellar structure formed in the thin film is characterized by $L=3.45 \mathrm{~nm}$ (long period) with a more dense sublayer $1.35-\mathrm{nm}$ thick $\left(=\ell_{\mathrm{c}}\right)$, a dense sublayer $0.68-\mathrm{nm}$ thick $\left(=\ell_{\mathrm{i}}\right)$ and a less dense sublayer $0.74-\mathrm{nm}$ thick $\left(=\ell_{\mathrm{a}}\right)$, a positional distortion factor $g$ of 0.050 and $O_{s}=0.907$ (the mean polar angle $\bar{\varphi}$ between the orientation vector $\mathbf{n}$ of the horizontal lamellar structure and the out-of-plane direction of the film is $0^{\circ}$, and the standard deviation $\sigma_{\varphi}$ of the polar angle $\varphi$ is $4.50^{\circ}$ ). Overall, the analysis results indicate that a highly horizontally oriented, wellordered lamellar structure was formed in the nanoscale films. The bristles in the horizontal lamellar structure were laterally packed, with a tilt angle of $19.5^{\circ}$ with respect to the plane perpendicular to the film (or lamellar plane). The bristles in the adjacent lamellae are in a fully extended conformation and exhibit no interdigitation. In addition, the 

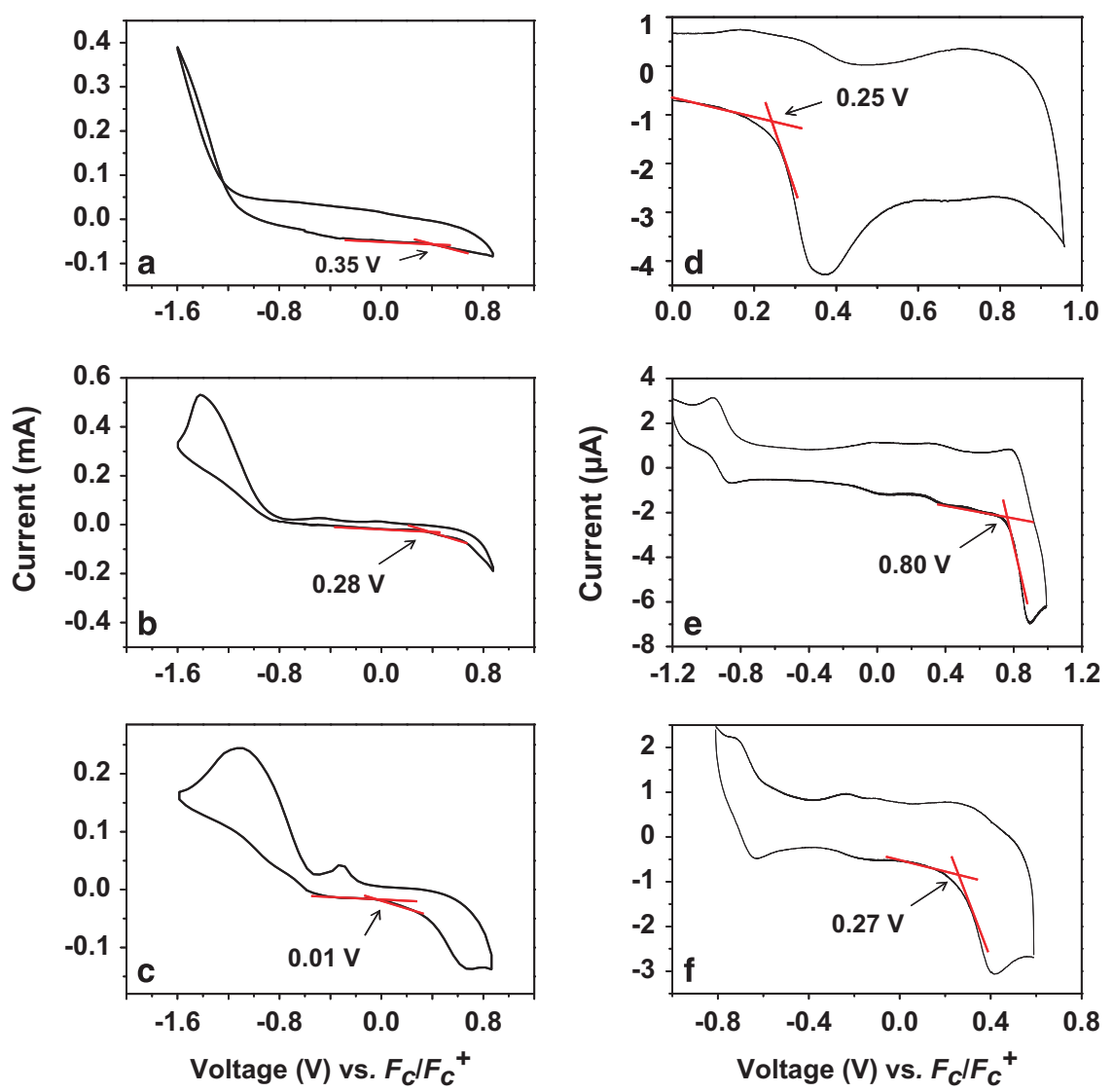

Figure 4 Cyclic voltammetric (CV) responses of triazole-containing brush polymers: (a) PG-Triazole-C 10 ; (b) PG-Triazole-C 2 P; (c) PG-Triazole-P; (d) PSTriazole-PEP; (e) PS-Triazole-PTCNE; (f) PS-Triazole-PTCNQ. For the PG-based brush polymers, CV measurements were carried out at $20^{\circ} \mathrm{C}$ in acetonitrile containing aqueous $0.1 \mathrm{~m}$ tetrabutylammonium tetrafluoroborate $\left(\left(n-\mathrm{C}_{4} \mathrm{H}_{9}\right)_{4} \mathrm{NPF}_{6}\right)$ using an electrochemical workstation (IM6ex impedance analyzer); gold and platinum gauze counter electrodes were used as the working electrode and auxiliary electrode, respectively, with an $\mathrm{Ag} / \mathrm{AgCl}(3.8 \mathrm{M} \mathrm{KCl})$ reference electrode. For the PS-based brush polymers, the measurements were conducted at $20^{\circ} \mathrm{C}$ in dehydrated methylene chloride $\left(\mathrm{CH}_{2} \mathrm{Cl}_{2}\right)$ containing $0.1 \mathrm{~m}$ tetrabutylammonium perchlorate $\left(\left(n-\mathrm{C}_{4} \mathrm{H}_{9}\right)_{4} \mathrm{NClO}_{4}\right)$; the working and auxiliary electrodes were a glassy carbon disk electrode $(2 \mathrm{~mm}$ in diameter) and a platinum wire, respectively, and the reference electrode was $\mathrm{Ag} / \mathrm{AgCl} / \mathrm{CH}_{3} \mathrm{CN} /\left(n-\mathrm{C}_{4} \mathrm{H}_{9}\right)_{4} \mathrm{NPF}_{6}$. A scan rate of $100 \mathrm{mVs}^{-1}$ was used. All potentials are referenced to ferrocene/ferricinium $\left(F_{\mathrm{c}} / F_{\mathrm{c}}{ }^{+}\right)$.

PG backbones are also in a fully extended conformation. The packed bristles, however, could not form regular lattices.

The scattering patterns of the other polymer films were featureless, except for two isotropic scattering rings (Figures $5 \mathrm{~b}-\mathrm{f}$ ), verifying their amorphous nature. The $d$-spacing values of the scattering rings in the low-angle regions were estimated to be $2.06 \mathrm{~nm}$ for PG-Triazole- $\mathrm{C}_{2} \mathrm{P}$, $2.00 \mathrm{~nm}$ for PG-Triazole-P, $4.30 \mathrm{~nm}$ for PS-Triazole-PEP, $4.21 \mathrm{~nm}$ for PS-Triazole-PTCNE and $4.23 \mathrm{~nm}$ for PS-Triazole-PTCNQ. These $d$-spacing values might correspond to the mean interdistances of polymer chains. The $d$-spacing values of the scattering rings in the high-angle regions were determined to be $0.48 \mathrm{~nm}$ for PG-Triazole$\mathrm{C}_{2} \mathrm{P}, \quad 0.47 \mathrm{~nm}$ for PG-Triazole-P, $0.49 \mathrm{~nm}$ for PS-Triazole-PEP, $0.49 \mathrm{~nm}$ for PS-Triazole-PTCNE and $0.49 \mathrm{~nm}$ for PS-TriazolePTCNQ, which originate from the mean interdistances of the bristles.

Figure 7 a shows a representative $\mathrm{XR}$ profile of a PG-Triazole- $\mathrm{C}_{10}$ film. The XR profile reveals Bragg reflection peaks at approximately $q_{\mathrm{z}}=1.85$ and $3.73 \mathrm{~nm}^{-1}$ (which correspond to the first- and secondorder reflections of the horizontal lamellar structure, respectively), in addition to Kiessig fringes ${ }^{37}$ at high frequency, which are attributed to the film thickness (Figure 7a); $q_{\mathrm{z}}$ is the magnitude in the $z$-direction of the scattering vector $\mathbf{q}$. The XR profile was satisfactorily fitted using the Parratt algorithm based on a three-sublayer model. ${ }^{19,24,38}$ This analysis revealed that the film has an average electron density $\rho_{\mathrm{e}, \mathrm{f}}$ of $350.28 \mathrm{~nm}^{-3}$ (which corresponds to a mass density $\rho_{\mathrm{m}, \mathrm{f}}$ of $1.06 \mathrm{~g} \mathrm{~cm}^{-3}$ ) and a surface roughness of $0.42 \mathrm{~nm}$. In the horizontal lamellar structure, each lamella is composed of three sublayers: a more dense sublayer $\left(\ell_{\mathrm{c}}=1.35 \mathrm{~nm}\right.$ and $\left.\rho_{\mathrm{e}, \mathrm{c}}=397.16 \mathrm{~nm}^{-3}\right)$, a dense sublayer $\left(\ell_{\mathrm{i}}=0.68 \mathrm{~nm}\right.$ and $\left.\rho_{\mathrm{e}, \mathrm{i}}=323.37 \mathrm{~nm}^{-3}\right)$, and a less dense sublayer $\left(\ell_{\mathrm{a}}=0.74 \mathrm{~nm}\right.$ and $\left.\rho_{\mathrm{e}, \mathrm{a}}=312.59 \mathrm{~nm}^{-3}\right)$. The thicknesses of these sublayers are in good agreement with those determined by GIXS analysis. The determined structural details for the PG-Triazole- $\mathrm{C}_{10}$ film are schematically illustrated in Figures $6 \mathrm{~d}$ and e.

Representative XR profiles of the other polymer films are shown in Figures $7 \mathrm{~b}-\mathrm{f}$. The XR profiles exhibit only Kiessig fringes at high frequencies. The XR data were successfully fitted using the Parratt algorithm based on a single layer. The $\rho_{\mathrm{e}, \mathrm{f}}$ value was determined to be $324.1 \mathrm{~nm}^{-3} \quad\left(\rho_{\mathrm{m}, \mathrm{f}}=1.01 \mathrm{~g} \mathrm{~cm}^{-3}\right)$ for PGTriazole- $\mathrm{C}_{2} \mathrm{P}, \quad 314.0 \mathrm{~nm}^{-3}\left(\rho_{\mathrm{m}, \mathrm{f}}=0.99 \mathrm{~g} \mathrm{~cm}^{-3}\right)$ for PG-Triazole-P, $324.6 \mathrm{~nm}^{-3}\left(\rho_{\mathrm{m}, \mathrm{f}}=0.98 \mathrm{~g} \mathrm{~cm}^{-3}\right)$ for PS-Triazole-PEP, $336.9 \mathrm{~nm}^{-3}$ $\left(\rho_{\mathrm{m}, \mathrm{f}}=1.03 \mathrm{~g} \mathrm{~cm}^{-3}\right)$ for PS-Triazole-PTCNE and $372.3 \mathrm{~nm}^{-3}$ $\left(\rho_{\mathrm{m}, \mathrm{f}}=1.14 \mathrm{~g} \mathrm{~cm}^{-3}\right)$ for PS-Triazole-PTCNQ. Overall, the $\rho_{\mathrm{e}, \mathrm{f}}$ values increase in the order PG-Triazole- $\mathrm{P}<\mathrm{PG}$-Triazole- $\mathrm{C}_{2} \mathrm{P}<\mathrm{PS}$-Triazole$\mathrm{PEP}<\mathrm{PS}$-Triazole-PTCNE $<$ PG-Trizaole- $\mathrm{C}_{10}<\mathrm{PS}$-Triazole-PTCNQ. In addition, these polymer films were determined to exhibit surface 

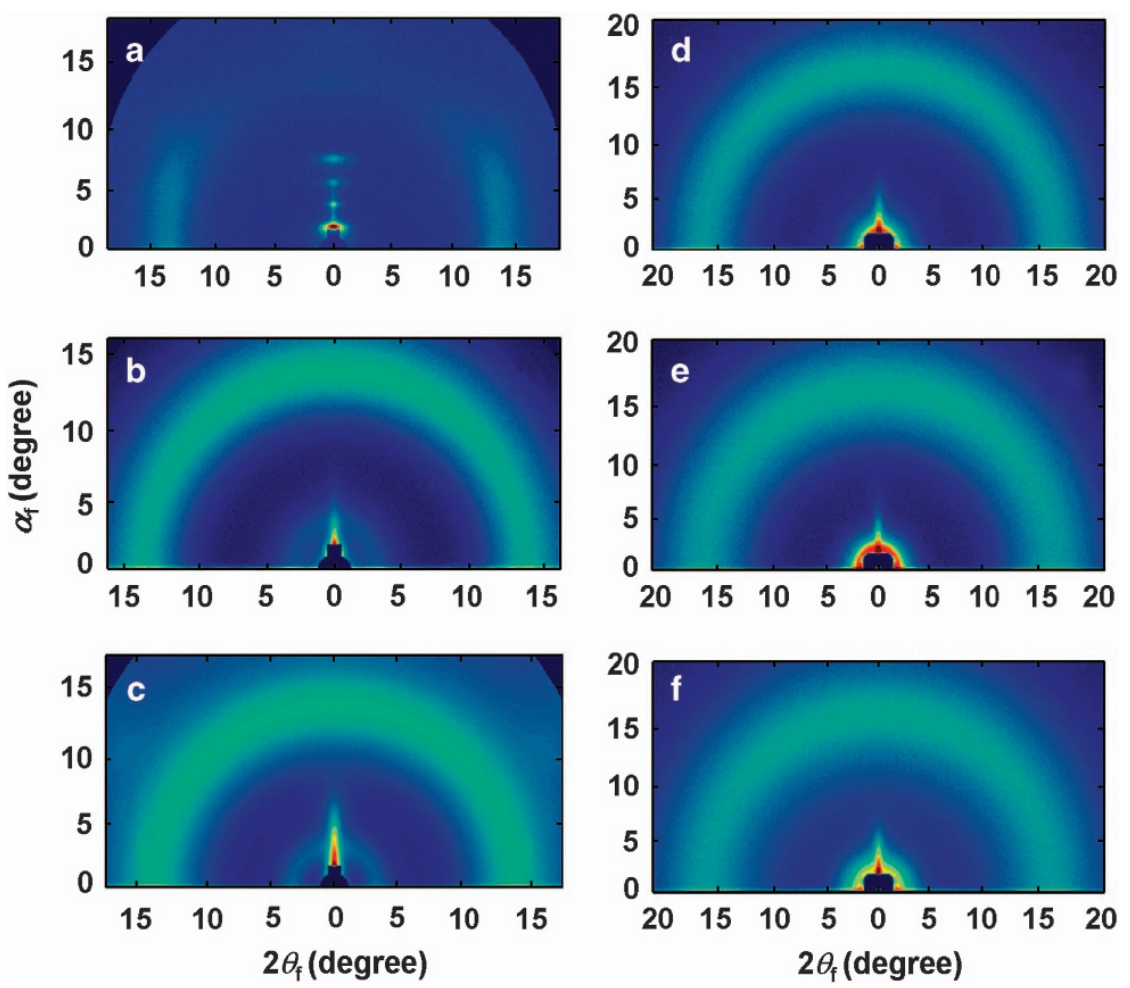

Figure 5 Representative synchrotron 2D GIXS patterns of triazole-containing brush polymer films $(10-65 \mathrm{~nm}$ thick) coated onto Si substrates; the patterns were collected under the following chosen conditions (the wavelength $\lambda$ and incident angle $\alpha_{\mathrm{i}}$ of X-ray beam and sample-to-detector distance (SDD)): (a) PG-

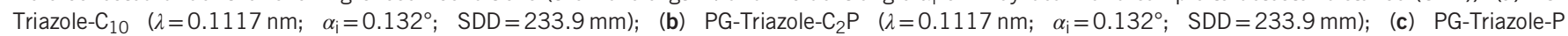
$\left(\lambda=0.1166 \mathrm{~nm} ; \alpha_{\mathrm{i}}=0.154^{\circ} ; \mathrm{SDD}=229.0 \mathrm{~mm}\right) ;(\mathbf{d})$ PS-Triazole-PEP $\left(\lambda=0.1381 \mathrm{~nm} ; \alpha_{\mathrm{i}}=0.142^{\circ} ; \mathrm{SDD}=125.0 \mathrm{~mm}\right) ;(\mathrm{e})$ PS-Triazole-PTCNE $(\lambda=0.1381 \mathrm{~nm}$; $\left.\alpha_{\mathrm{i}}=0.142^{\circ} ; \mathrm{SDD}=125.0 \mathrm{~mm}\right) ;(\mathrm{f})$ PS-Triazole-PTCNQ $\left(\lambda=0.1381 \mathrm{~nm} ; \alpha_{\mathrm{i}}=0.142^{\circ} ; \mathrm{SDD}=125.0 \mathrm{~mm}\right)$.

roughnesses of $0.10-0.60 \mathrm{~nm}$, confirming that high-quality films were produced by conventional solution coating and drying processes.

Having determined these structures and properties, we further investigated the triazole-containing polymers' electrical memory characteristics by incorporating them as active layers into devices with $\mathrm{Al}$ top and bottom electrodes (Figure 8a). All of the PG-Triazole- $\mathrm{C}_{10}$ devices, as well as all of the PG-Triazole- $\mathrm{C}_{2} \mathrm{P}$ devices, exhibited no electrical switching behaviors over the voltage range -8 to $+8 \mathrm{~V}$, as shown in Figures $8 \mathrm{~b}-\mathrm{i}$ and Supplementary Figures S5a-h. These current-voltage $(I-V)$ behaviors indicate that both PG-Triazole- $\mathrm{C}_{10}$ and PG-Triazole- $\mathrm{C}_{2} \mathrm{P}$ are dielectric polymers, rather than electrical memory materials.

Similar dielectric behaviors were observed for the PG-Triazole-P devices fabricated with $40 \mathrm{~nm}$ or thicker films (Figure $8 \mathrm{j}$ and Supplementary Figure S5i). In contrast, the devices with $30 \mathrm{~nm}$ or thinner PG-Triazole-P films nicely exhibited excellent write-onceread-many-times (WORM) memory behaviors, as presented in Figures $8 \mathrm{k}-\mathrm{m}$ and Supplementary Figures S5j-l. For example, the 30-nm thick PG-Triazole-P film device initially exhibited a high resistance (that is, OFF-state). When a positive voltage was applied, the device exhibited an abrupt increase in current of approximately $+5.0 \mathrm{~V}$ (which corresponds to the critical voltage $V_{c, \mathrm{ON}}$ to switch on the device). In the device, the OFF-to-ON transition can function as a 'writing' process. After being switched on, the device retained its ON-state during reverse and forward voltage sweeps and even after the power was turned off (Figure 8k). The ON/OFF current ratio was estimated to be very high $\left(10^{8}-10^{9}\right)$, depending on the reading voltage chosen. We observed similar WORM (that is, permanent) memory behavior in negative voltage sweeps (Supplementary
Figure S5j). Overall, the 30-nm thick film device exhibited a unipolar permanent memory behavior. Similar unipolar permanent memories were observed for 20- and 10-nm thick polymer film devices (Figures $81-\mathrm{m}$ and Supplementary Figures $\mathrm{S} 5 \mathrm{k}-\mathrm{l}$ ). The $V_{\mathrm{c}, \mathrm{ON}}$ value, however, was slightly lower in thinner-film devices, as was the ON/OFF current ratio.

Here a question arises: why do PG-Triazole- $\mathrm{C}_{10}$ and PG-Triazole$\mathrm{C}_{2} \mathrm{P}$ exhibit no memory behaviors, whereas $\mathrm{PG}$-Triazole-P exhibits excellent electrical memory behavior? Some clues to this interesting trend are observed in their chemical natures, properties (in particular, molecular orbitals) and thin-film morphologies, as follows.

The polymers are, in fact, in the same family from the viewpoint of their backbones and triazole-containing bristles, as shown in Figure 1. The individual polymers, however, have different end groups in the triazole moiety of their bristles. The end group is $n$-decyl for PG-Triazole- $C_{10}$, ethylenylphenyl for PG-Triazole- $\mathrm{C}_{2} \mathrm{P}$ and phenyl for PG-Triazole-P. In view of the inductive effect, the $n$-decyl and ethylenylphenyl end groups can be classified as electron donors, whereas the phenyl end group can be classified as either a weak electron donor or weak electron acceptor, depending on its chemical environment. Indeed, the electron-donating abilities of the end groups can be ranked in the increasing order of phenyl «ethylenylpheny$1<n$-decyl. In addition, the ethylene oxide backbone and methylenyl linker of the polymers can be classified as electron donors. The triazole unit has three nitrogen atoms with a lone electron pair and two possible resonance structures. Because of the relatively strong inductive effect of three nitrogen atoms, which can overwhelm the resonance effect, the triazole moiety can be classified as an electron donor. However, from the viewpoint of the resonance effect, neither 

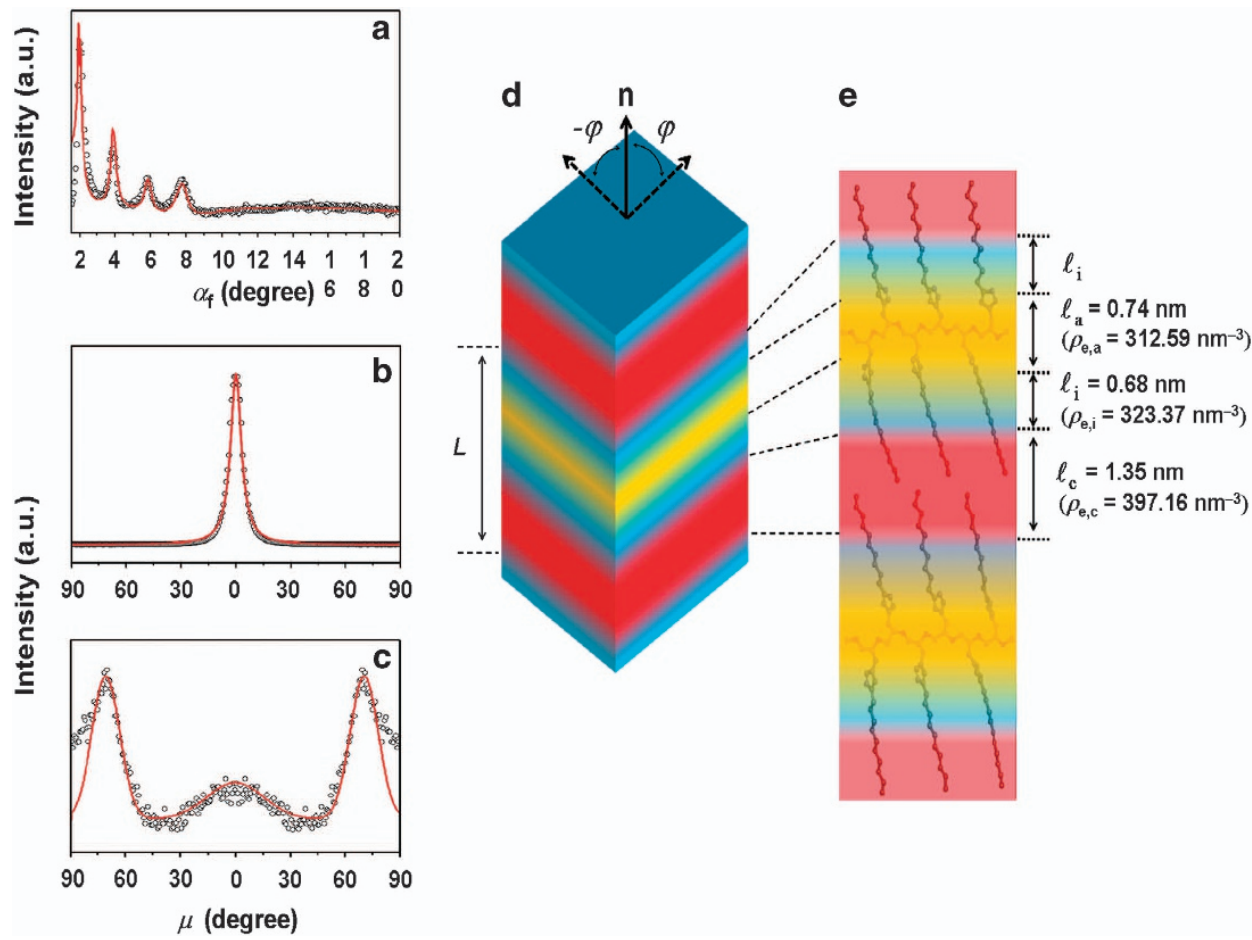

Figure 6 Scattering profiles were extracted from the 2D GIXS pattern of the PG-Triazole- $\mathrm{C}_{10}$ film in Figure 5a: (a) out-of-plane scattering profile extracted along the $\alpha_{\mathrm{f}}$ direction at $2 \theta_{\mathrm{f}}=0^{\circ}$, where the black symbols are the measured data and the red solid line was obtained by fitting the data using the GIXS formula derived with a structural model in panel (d); (b and c) azimuthal profiles extracted at $1.91^{\circ}$ and $13.48^{\circ}$, respectively; (d) lamellar model with three sublayers, which are defined with a set of parameters (a more dense sublayer with a thickness $\ell_{\mathrm{c}}$, a dense sublayer with a thickness $\ell_{\mathrm{i}}$, a less dense sublayer with a thickness $\left.\ell_{\mathrm{a}}\right)$ and long period $\left.L\left(=\ell_{\mathrm{c}}+2 \ell_{\mathrm{i}}+\ell_{\mathrm{a}}\right)\right)$, where $\mathbf{n}$ is the orientation vector of the structure model and $\varphi$ is the polar angle between the $\mathbf{n}$ vector and the out-of-plane of the film; (e) schematic of molecular chain conformations and packing orders in PG-Triazole- $\mathrm{C}_{10}$ films.

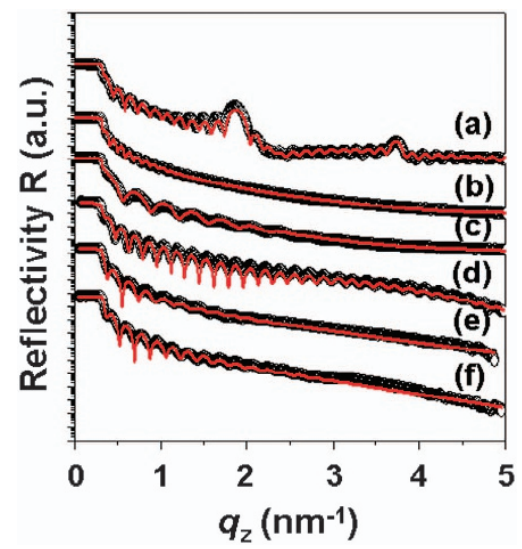

Figure 7 Representative XR profiles of triazole-containing brush polymer films coated onto $\mathrm{Si}$ substrates: (a) PG-Triazole- $\mathrm{C}_{10}$; (b) PG-Triazole- $\mathrm{C}_{2} \mathrm{P}$;

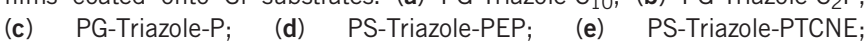
(f) PS-Triazole-PTCNQ. In each XR profile, the symbols are the measured data, and the solid line represents the fit curve.

the ethylenylphenyl nor the $n$-decyl end group can positively contribute to the stabilization of the triazole moiety. In contrast, the phenyl end group can provide a certain level of stabilization to the triazole moiety because of its resonance structures. When the inductive and resonance effects of the end groups are taken into account, the observed $I-V$ results collectively indicate that the triazole moieties in the PG-based polymer essentially require strong supports by substituents with resonance stabilization capability for trapping and transporting charges to exhibit electrical memory behaviors.
The triazole moieties, which are inductively supported by the electron-donor backbone and methylenyl linker, may be able to trap charges under an applied electric field. The trapped charges could then be further stabilized by the phenyl end group with resonance stabilization ability. These cooperative effects would enable the triazole moieties in PG-Triazole-P devices to demonstrate excellent permanent memory characteristics. The other triazole-containing PG polymer devices in which the triazole moieties do not benefit from any resonance stabilization could, however, exhibit no electrical memory behavior.

With respect to the molecular orbitals (HOMO and LUMO levels), the energy barriers for hole injection from the Al electrode (work function, $\Phi=-4.28 \mathrm{eV}$ ) into the active polymer film in the device are estimated to be $0.87 \mathrm{eV}$ for PG-Triazole- $\mathrm{C}_{10}, 0.80 \mathrm{eV}$ for PG-Triazole$\mathrm{C}_{2} \mathrm{P}$ and $0.53 \mathrm{eV}$ for PG-Triazole-P. The energy barriers for electron injection from the $\mathrm{Al}$ electrode into the active polymer film were estimated to be $3.96 \mathrm{eV}$ for PG-Triazole- $\mathrm{C}_{10}, 3.69 \mathrm{eV}$ for PG-Triazole$\mathrm{C}_{2} \mathrm{P}$ and $3.76 \mathrm{eV}$ for PG-Triazole-P. These energy barriers suggest that the electrical conduction processes in the devices predominantly involve hole injection. Indeed, the permanent memory behaviors observed in the PG-Triazole-P devices might be driven mainly by hole injection. For such favorable hole injection, the triazole moieties are rich in electrons and can be stabilized by the resonance nature of the phenyl end group. This fact can have a key role in trapping and transporting the charges injected from the electrode, exhibiting $p$-type electrical switching.

With respect to nanoscale thin-film morphology, both PG-Triazole$\mathrm{C}_{2} \mathrm{P}$ and PG-Triazole-P are amorphous, whereas PG-Triazole- $\mathrm{C}_{10}$ is crystalline, as previously discussed. Because of their amorphous 

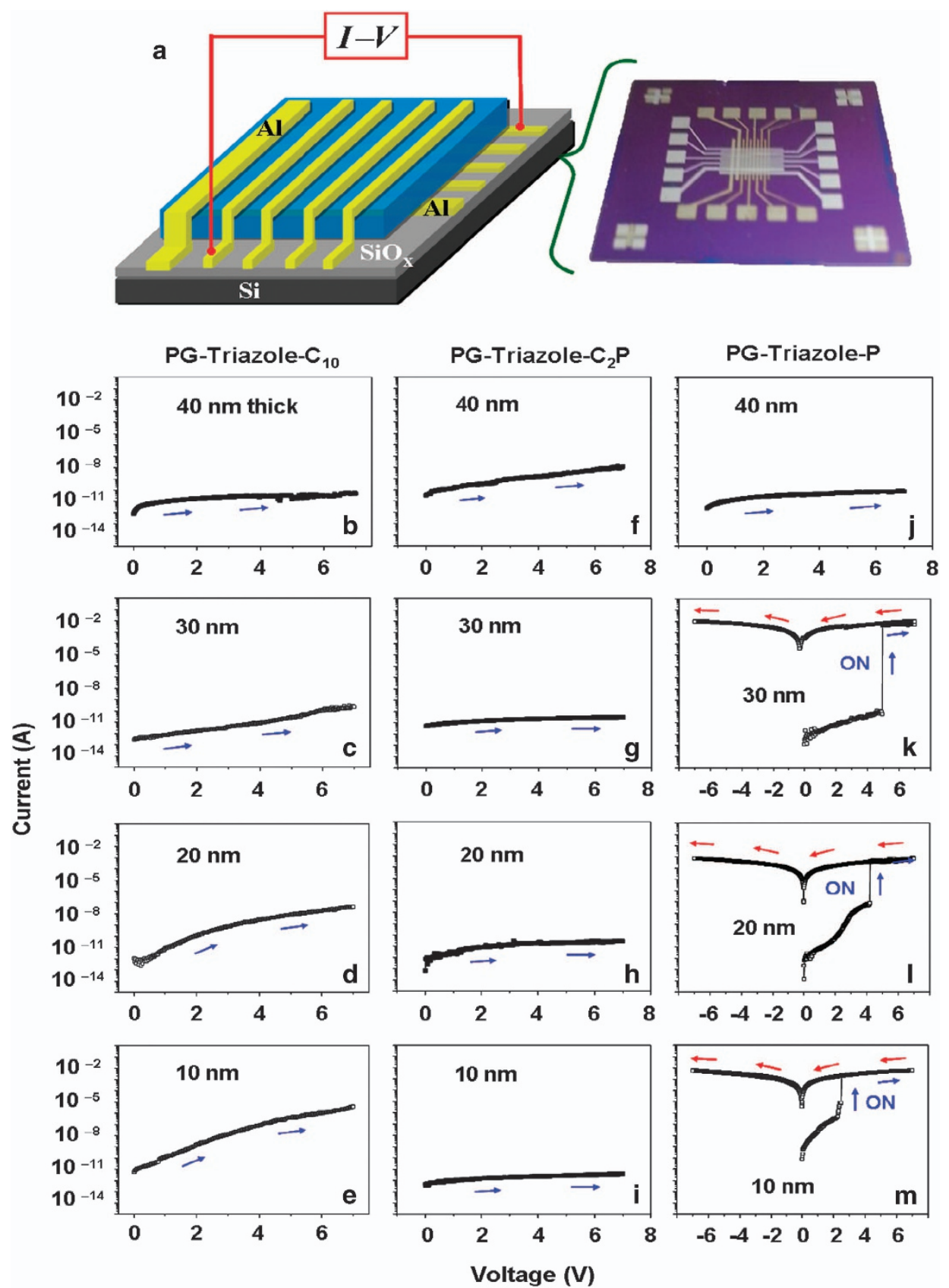

Figure 8 Representative $I-V$ curves of the Al/polymer/AI devices, which were measured under ambient air conditions with a compliance current set to $0.01 \mathrm{~A}$ : (a) device structure; (b-e) PG-Triazole- $\mathrm{C}_{10}$ films; ( $\left.\mathbf{f}-\mathbf{i}\right)$ PG-Triazole- $\mathrm{C}_{2} \mathrm{P}$ films; (j-m) PG-Triazole-P films. The electrode contact area was $0.1 \times 0.1 \mathrm{~mm}{ }^{2}$.

nature, the triazole moieties in the PG-Triazole- $\mathrm{C}_{2} \mathrm{P}$ and PG-Triazole$\mathrm{P}$ films have relatively short interdistances $(0.47-0.48 \mathrm{~nm}$ intramolecularly and $2.00-2.06 \mathrm{~nm}$ intermolecularly). In PG-Triazole- $\mathrm{C}_{10}$ films with horizontal lamellar structures, the triazole moieties are positioned with a mean interdistance of $0.47 \mathrm{~nm}$ in the in-plane direction of the films and mean interdistances of ca. $0.74 \mathrm{~nm}$ and ca. $2.71 \mathrm{~nm}$ in the out-plane direction of the films. These morphology results depict the triazole moieties as being locally positioned with a distribution of interdistances throughout the whole film. Given the previously discussed charge affinity of the triazole moiety, these morphology results suggest that electrical conduction in the devices can be driven mainly by the hopping process of charges under an applied electric field, where the triazole moieties locally positioned with a distribution in the film are used as stepping stones. Therefore, electrical conduction via a hopping process may be relatively easier in the PG-Triazole- $\mathrm{P}$ and $\mathrm{PG}$-Triazole- $\mathrm{C}_{2} \mathrm{P}$ devices than in the PG-Triazole- $\mathrm{C}_{10}$ devices. Because of this hopping nature in the electrical conduction mechanism, the charge mobility in the polymer films can be limited to a certain level. Such a limited charge mobility is indirectly evident in the PG-Triazole-P device with a film thickness window (10-30-nm thick) for unipolar WORM memory behaviors, as previously discussed.

Collectively, the excellent $p$-type unipolar permanent memory performance of PG-Triazole-P in the devices is mainly driven by the phenyl-linked triazole moieties, which can favorably trap charges under an applied electric field, stabilize the trapped charges properly 

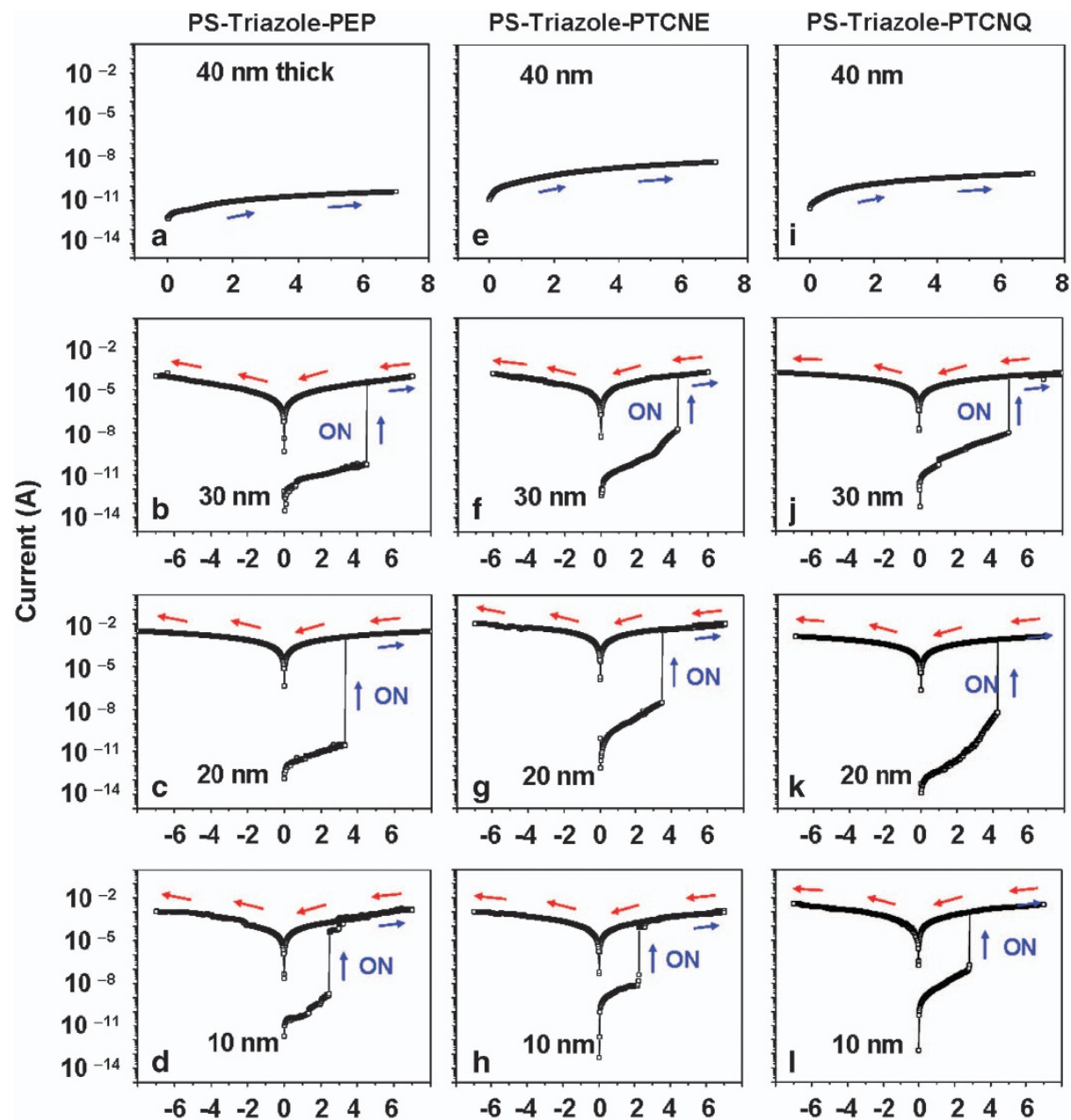

$\begin{array}{rrrrrrrr}-6 & -4 & -2 & 0 & 2 & 4 & 6\end{array}$
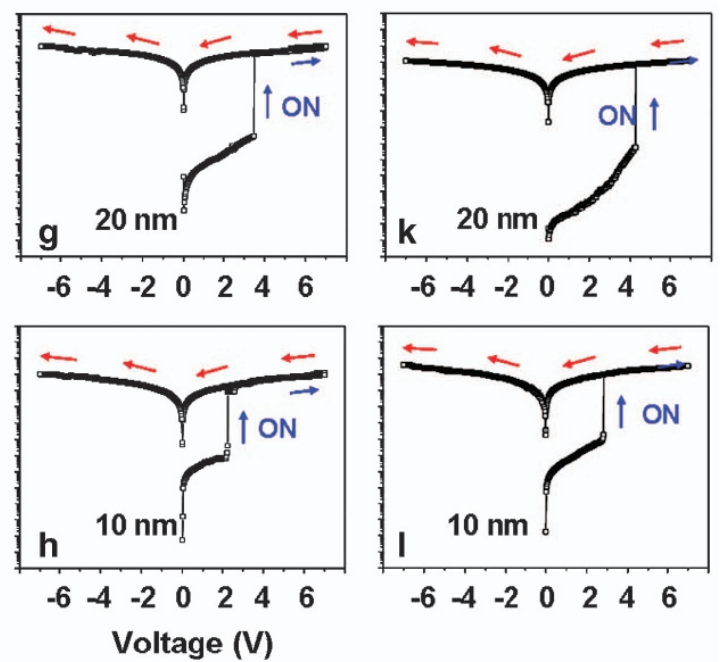

Figure 9 Representative $I-V$ curves of the Al/polymer/AI devices, which were measured under ambient air conditions with a compliance current set to $0.01 \mathrm{~A}$ : (a-d) PS-Triazole-PEP films; (e-h) PS-Triazole-PTCNE films; (i-l) PS-Triazole-PTCNQ films. The electrode contact area was $0.1 \times 0.1 \mathrm{~mm}$.

and additionally transport charges as stepping stones via the hopping process. Such remarkable functions of the phenyl-linked triazole moieties originate from the positive cooperation between the charge affinities (that is, inductive powers) of the electron-donating triazole moiety itself, together with the backbone and methylenyl linkers, and the charge stabilization power of the phenyl-linked triazole moieties owing to the linked phenyl group. In contrast, the absence of electrical memory behavior in the other PG-based polymers is caused by a lack of charge stabilization in the triazole moieties supported only with the electron-donating backbone, methylenyl linkers and end groups.

Given the aforementioned excellent memory characteristics of PG-Triazole-P, the device performance of the three PS-based polymers was additionally tested as material systems composed of triazole moieties having end groups with extended $\pi$-conjugation lengths and electron-accepting powers. Here we note that the PS backbone was confirmed to be dielectric (Supplementary Figure S6). As shown in Figures 9a, e and i, the polymer films with a thickness of $40 \mathrm{~nm}$ behave as dielectric films during positive voltage sweeps. Such dielectric behaviors are also observed in negative voltage sweeps (Supplementary Figures S7a, e and i). Specifically, the 40-nm thick films exhibited no memory behavior. Thinner polymer films, however, exhibited WORM memory behaviors in both positive and negative voltage sweeps (Figure 9 and Supplementary Figure S7). Furthermore, the $V_{c, \text { ON }}$ value as well as the ON/OFF current ratio slightly decreased with decreasing film thickness. Overall, the observed $I-V$ characteristics and film thickness dependencies are similar to those measured for PG-Triazole-P. Surprisingly, these results collectively suggest that the electrical memory behavior and film thickness dependency such as those observed for the PG-Triazole-P films are not substantially influenced by the ethynylphenyl (that is, an extended $\pi$-conjugation moiety) and TCNE or TCNQ (that is, electron-accepting moieties) added to the phenyl end group of the triazole moiety.

The additional ethynylphenyl, TCNE and TCNQ moieties, however, were observed to cause changes in the molecular orbitals of PG-Triazole-P, as previously discussed. Because of such additions, the HOMO level was somewhat reduced, whereas the LUMO level was substantially lowered. As a result, the energy barriers for hole injection into the HOMO levels from the $\mathrm{Al}$ electrodes were relatively increased to $0.77 \mathrm{eV}$ for PS-Triazole-PEP, $1.32 \mathrm{eV}$ for PS-Triazole-PTCNE and $0.79 \mathrm{eV}$ for PS-Triazole-PTCNQ. The energy barriers for electron injection into the LUMO levels from the electrodes were substantially reduced to $2.32 \mathrm{eV}$ for PS-Triazole-PEP, $0.70 \mathrm{eV}$ for PS-TriazolePTCNE and $0.55 \mathrm{eV}$ for PS-Triazole-PTCNQ. These energy barriers suggest that the electrical conduction processes in the PS-Triazole-PEP devices are predominantly governed by hole injection, as in the case of the PG-Triazole-P devices, whereas the PS-Triazole-PTCNE and 

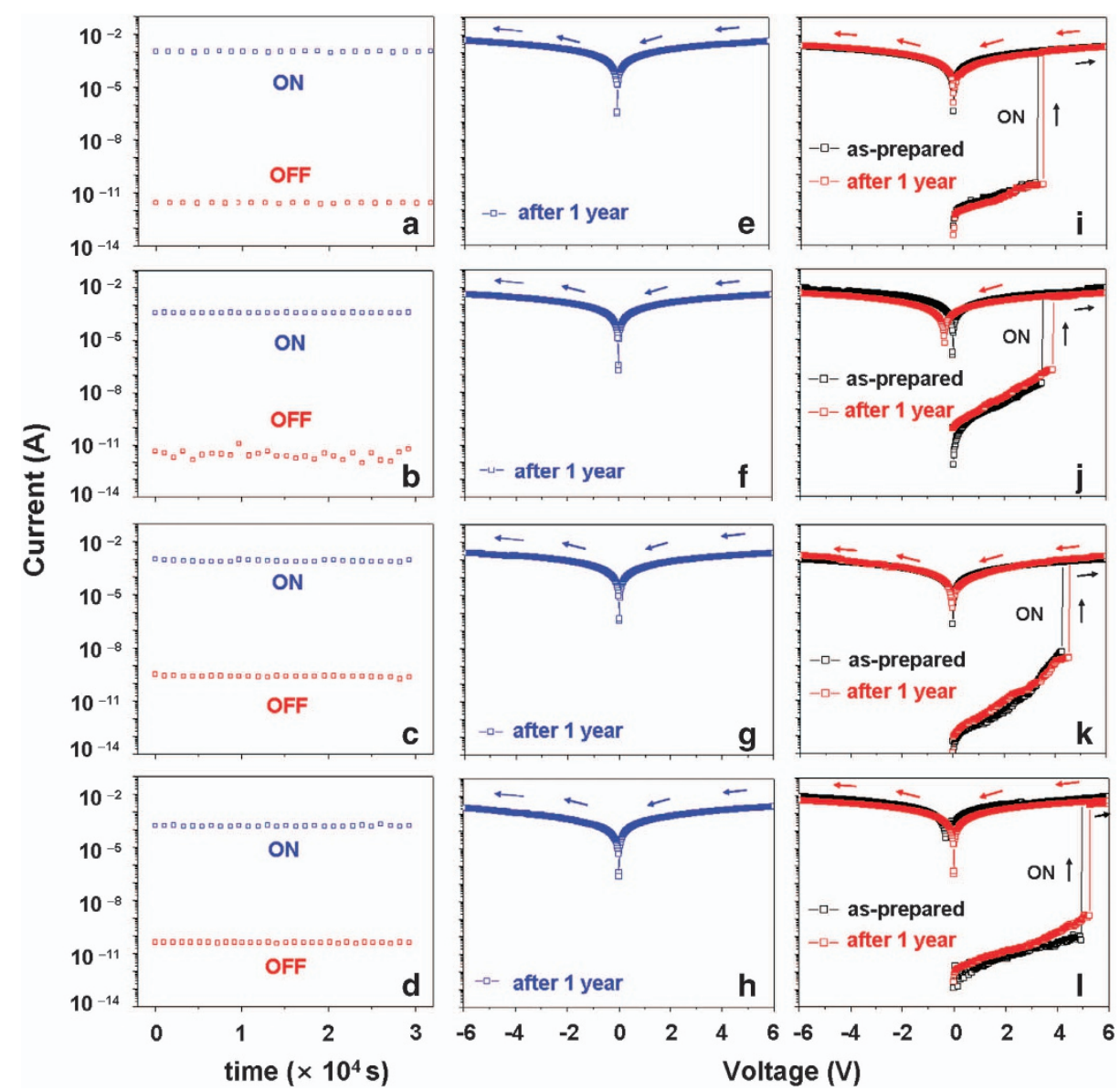

Figure 10 Stabilities and reliabilities of the devices fabricated with triazole-containing brush polymers. Retention times of the ON- and OFF-states of the $20 \mathrm{~nm}$ thick polymer devices, which were measured under ambient air conditions using a reading voltage of $1.0 \mathrm{~V}$ and a compliance current of $0.01 \mathrm{~A}$ : (a) PG-Triazole-P; (b) PS-Triazole-PEP; (c) PS-Triazole-PTCNE; (d) PS-Triazole-PTCNQ. Stabilities of the 30-nm-thick polymer devices switched-on, which were measured with a compliance current of $0.01 \mathrm{~A}$ after storage under ambient air conditions for 1 year: (e) PG-Triazole-P; (f) PS-Triazole-PEP; (g) PS-Triazole-PTCNE; (h) PS-Triazole-PTCNQ. Reliabilities of the 30-nm-thick polymer devices, which were measured with a compliance current of 0.01 A after storage under ambient air conditions for 1 year: (i) PG-Triazole-P; (j) PS-Triazole-PEP; (k) PS-Triazole-PTCNE; (I) PS-Triazole-PTCNQ. The electrode contact area was $0.1 \times 0.1 \mathrm{~mm}^{2}$.

PS-Triazole-PTCNQ devices undergo conduction processes dominated by electron injection. Therefore, the addition of only an ethynylphenyl moiety to the triazole moiety still retains the p-type memory behavior. In contrast, the addition of an ethynylphenyl moiety together with an electron-accepting TCNE or TCNQ unit to the triazole moiety alters $p$-type memory behavior to $n$-type behavior.

The polymer devices that exhibit permanent memory behavior were further subjected to stability and reliability tests under ambient air conditions. Figures $10 \mathrm{a}-\mathrm{d}$ presents the stabilities of the OFF- and $\mathrm{ON}$-states examined at room temperature using a reading voltage of $+1.0 \mathrm{~V}$. For all devices, the OFF-state was well retained with no degradation for a test period of $3.0 \times 10^{4} \mathrm{~s}$. After the devices were switched to the $\mathrm{ON}$-state under an applied $+6.0 \mathrm{~V}$ potential at a compliance current of $0.01 \mathrm{~A}$, the $\mathrm{ON}$-state was well maintained with no degradation for a test period of $3.0 \times 10^{4} \mathrm{~s}$. Such ON-states were further retained after the devices were maintained under ambient air conditions for 1 year, demonstrating excellent permanent memory performance (Figures 10e-h). Moreover, we confirmed that all devices still functioned properly after being maintained under ambient air conditions for 1 year (Figures 10i-1).

Overall, the PG-Triazole-P and PS-Triazole-PEP devices exhibited p-type unipolar WORM memory behaviors with high stability and reliability, whereas the PS-Triazole-PTCNE and PS-Triazole-PTCNQ devices exhibited $n$-type unipolar permanent memory behaviors with high stability and reliability.

The $I-V$ profiles of the polymer devices in the OFF-state as well as in the ON-state were further analyzed using various conduction models. ${ }^{18,39-43}$ The analysis results are given in Supplementary Figure S8. The $I-V$ profiles of the devices in the OFF-state are dominated by the combination of an ohmic conduction and a trap-limited space-charge limited conduction Supplementary Figures S8a-d), whereas the $I-V$ profiles in the ON-state predominantly exhibit ohmic conduction (Supplementary Figures S8e-h).

\section{CONCLUSIONS}

Brush PG- and PS-based polymers containing a triazole moiety per bristle in two different series were synthesized by azide-alkyne click reactions, and their thin film morphologies and properties, including their electrical memory characteristics, were examined: (i) PG-Triazole- $\mathrm{C}_{10}, \quad$ PG-Triazole- $\mathrm{C}_{2} \mathrm{P}$ and PG-Triazole-P; and (ii) PS-Triazole-PEP, PS-Triazole-PTCNE, and PS-Triazole-PTCNQ. These brush polymers are thermally stable to at least $236^{\circ} \mathrm{C}$. They exhibit $T_{\mathrm{g}}$ values that range from 43 to $125^{\circ} \mathrm{C}$, depending on the backbone and bristle end groups; however, only PG-Triazole- $\mathrm{C}_{10}$ is 
crystalline, exhibiting a $T_{\mathrm{m}}\left(123^{\circ} \mathrm{C}\right)$. Their molecular orbitals and band gaps were determined by UV-vis spectroscopic and cyclic voltammetric analysis. In particular, the incorporation of electronaccepting TCNE and TCNQ into the triazole-containing bristle significantly reduced the LUMO level and band gap. Furthermore, all brush polymers are soluble in organic solvents, resulting in highquality thin films (surface roughness $\leqslant 0.60 \mathrm{~nm}$ ) via conventional coating processes.

Nanoscale thin-film morphologies of the brush polymers were investigated in detail by synchrotron GIXS and XR analyses. PG-Triazole- $C_{10}$ was observed to form a well-ordered horizontal lamellar structure, which was driven mainly by the lateral ordering of the outer part of $n$-decyl end groups in the bristle without interdigitation, where the backbone and bristle were in fully extended conformations. In contrast, the other brush polymers formed amorphous films. From these analyses, the structural details, including electron and mass densities, were determined. In particular, the triazole moieties (which correlate to electrical memory behavior) in the amorphous films were observed to be locally distributed with relatively shorter interdistances $(\leqslant 2.06 \mathrm{~nm})$ across the top and bottom electrodes than those $(\leqslant 2.71 \mathrm{~nm})$ in the crystalline films.

Devices fabricated with $10-30-\mathrm{nm}$ thick films of PG-Triazole-P interestingly demonstrated excellent $p$-type unipolar WORM memory behaviors with a high ON/OFF current ratio, low power consumption, long retention time and high reliability. Similar permanent memory performances were observed for the devices fabricated with $10-30$-nm thick films of PS-based polymers. In contrast, the devices fabricated with films of PG-Triazole- $\mathrm{C}_{10}$ and PG-Triazole- $\mathrm{C}_{2} \mathrm{P}$ exhibited no electrical memory behavior. Considering the dielectric nature of PECH- and PS-based polymers, the device test results collectively confirm that the excellent permanent memory performances of the PG-Triazole-P devices and the PS-based polymer devices originate from the electron-donating triazole moieties supported strongly with an end group or linker with the ability to stabilize charges; without such support based on the resonance effect, the triazole moieties alone could not produce any electrical memory characteristics. Furthermore, the incorporation of a strong electron-accepting TCNE or TCNQ into the ethynylphenyl unit linked to the triazole moiety changed the memory mode, from $p$-type to $n$-type, by reducing the LUMO level substantially with regard to the work function of the electrode.

All memory behaviors observed in this study were observed to be governed by a mechanism involving the combination of ohmic and trap-limited space-charge limited conductions and the hopping process of charges. Because of the nature of the charge-hopping process using the triazole moieties locally distributed throughout the polymer films, the charge mobility across the polymer film layer in the device may be limited. Such a limited charge mobility was evidenced by the film thickness dependency of the devices.

Overall, this study demonstrated for the first time that the formation of triazole moieties accompanied by linker(s) or end group(s) having a resonance effect (which can provide a charge stabilization power) by using azide-alkyne click chemistry is a very powerful synthetic route to develop high-performance electrical memory polymers. The memory mode can be tuned by further changing the linker(s) or end group(s) in the triazole moieties. PG-Triazole-P and PS-Triazole-PEP are highly suitable for the lowcost mass production of polarity-free programmable $p$-type permanent memory devices that can be operated with very low power consumption, a high ON/OFF current ratio and high stability and reliability. PS-Triazole-PTCNE and PS-Trizaole-PTCNQ are highly suitable materials for the low-cost mass production of $n$-type unipolar permanent memory devices with high performance.

\section{CONFLICT OF INTEREST}

The authors declare no conflict of interest.

\section{ACKNOWLEDGEMENTS}

This study was supported by the National Research Foundation (NRF) of Korea (Doyak Program 2011-0028678), the Ministry of Science, ICT and Future Planning (MSIP) and the Ministry of Education (BK21 Plus Program and Global Excel Program), Republic of Korea. This work was also supported by the Ministry of Education, Culture, Sports, Science and Technology (MEXT), Japan (Grant-in-Aid for Scientific Research (B), No. 15H03863) and Tokyo Institute of Technology (STAR program-Supports for Tokyo Tech Advanced Researchers). The synchrotron X-ray scattering and reflectivity measurements at the Pohang Accelerator Laboratory were supported by MSIP, POSTECH Foundation and POSCO Company.

Author contributions: MR and TM designed the research and initiated the study. JM and PNS synthesized and characterized the materials. SS and YL conducted the polymer synthesis and fundamental characterization and sample preparations. YGK and DW carried out device fabrications and $I-V$ analysis. HL and BJR conducted GIXS and XR measurements and data analyses. MR, SS, YGK, HL, BJR and TM prepared the manuscript. All authors contributed to the discussion.

1 Kolb, H. C., Finn, M. G. \& Sharpless, K. B. Click chemistry: Diverse chemical function from a few good reactions. Angew. Chem. Int. Ed. 40, 2004-2021 (2001).

2 Espeel, P. \& Du Prez, F. E. "Click"-inspired chemistry in macromolecular science: matching recent progress and user expectations. Marcromolecules 48, 2-14 (2015).

3 Gauthier, M. A., Gibson, M. I. \& Klok, H.-A. Synthesis of functional polymers by postpolymerization modification. Angew. Chem. Int. Ed. 48, 48-58 (2009).

4 Sumerlin, B. S. \& Vogt, A. P. Macromolecular engineering through click chemistry and other efficient transformations. Macromolecules 43, 1-13 (2010),

5 Satoh, T., Nishikawa, N., Kawato, D., Suemasa, D., Jung, S., Kim, Y. Y., Ree, M. \& Kakuchi, T. Precise synthesis of a rod-coil type miktoarm star copolymer containing poly (n-hexyl isocyanate) and aliphatic polyester. Polym. Chem. 5, 588-599 (2014).

6 Kim, Y. Y., Jung, S., Kim, C., Ree, B. J., Kawato, D., Nishikawa, N., Suemasa, D. Isono, T., Kakuchi, T., Satoh, T. \& Ree, M. Hierarchical structures in thin films of miktoarm star polymers: poly( $n$-hexyl isocyanate)(12K)-poly( $\varepsilon$-caprolactone $)_{1-3}(5 \mathrm{~K})$. Marcromolecules 47, 7510-7524 (2014).

7 Tornøe, C. W., Christensen, C. \& Meldal, M. J. Peptidotriazoles on solid phase $[1,2,3]$-triazoles by regiospecific copper(i)-catalyzed 1,3-dipolar cycloadditions of terminal alkynes to azides. J. org. Chem. 67, 3057-3064 (2002).

$8 \mathrm{Li}$, Y., Tsuboi, K. \& Michinobu, T. Double click synthesis and second-order nonlinearities of polystyrenes bearing donor-acceptor chromophores. Marcromolecules 43 5277-5286 (2010)

9 Baskin, J. M., Prescher, J. A., Laughlin, S. T., Agard, N. J., Chang, P. V., Miller, I. A., Lo, A., Codelli, J. A. \& Bertozzi, C. R. Copper-free click chemistry for dynamic in vivo imaging. Proc. Natl Acad. Sci. USA 104, 16793-16797 (2007).

10 Hoyle, C. E., Lowe, A. B. \& Bowman, C. N. Thiol-click chemistry: A multifaceted toolbox for small molecule and polymer synthesis. Chem. Soc. Rev. 39, 1355-1387 (2010).

11 Gacal, B., Tasdelen, M. A., Hizal, G., Tunca, U., Yagci, Y. \& Demirel, A. L. Anthrancene-maleimide-based Diel-Alder "click chemistry" as a novel route to graft copolymers. Macromolecules 39, 5330-5336 (2006).

12 Koyama, Y., Yonekawa, M. \& Takata, T. New click chemistry: Click polymerization via 1,3-dipolar addition of homo-ditopic aromatic nitrile oxides formed in situ. Chem. Lett. 37, 918-918 (2008)

13 Singh, I., Zarafshani, Z., Lutz, J.-F. \& Heaney, F. Metal-free "click" chemistry: efficient polymer modification via 1,3-dipolar cycloaddition of nitrile oxides and alkynes. Macromolecules 42, 5411-5413 (2009).

14 Lee, Y.-G., Koyama, Y., Yonekawa, M. \& Takata, T. New click chemistry: polymerization based on 1,3-dipolar cycloaddition of a homo ditopic nitrile $\mathrm{N}$-oxide and transformation of the resulting polymers into reactive polymers. Macromolecules 42, 7709-7717 (2009)

15 Gutsmiedl, K., Wirges, C., Ehmke, V. \& Carell, T. Copper-free "click" modification of DNA via nitrile oxide-norbornene 1,3-dipolar cycloaddition. Org. Lett. 11, 2405-2048 (2009).

16 Scott, J. C. \& Bozano, L. D. Nonvolatile memory elements based on organic materials. Adv. Mater. 19, 1452-1463 (2007).

17 Ling, Q.-D., Liaw, D.-J., Zhu, C., Chan, D. S.-H., Kang, E.-T. \& Neoh, K.-G. Polymer electronic memories: materials, devices and mechanisms. Prog. Polym. Sci 33 917-978 (2008). 
18 Hahm, S. G., Ko, Y.-G., Kwon, W. \& Ree, M. Programmable digital polymer memories. Curr. Opin. Chem. Eng. 2, 79-87 (2013).

19 Lin, W. P., Liu, S. J., Gong, T., Zhao, Q. \& Huang, W. Polymer-based resistive memory materials and devices. Adv. Mater. 26, 570-606 (2014).

20 Ko, Y.-G., Hahm, S. G., Murata, K., Kim, Y. Y., Ree, B. J., Song, S., Michinobu, T. \& Ree, M. New fullerene-based polymers and their electrical memory characteristics. Macromolecules 47, 8154-8163 (2014).

21 Baek, S., Lee, D., Kim, J., Hong, S., Kim, O. \& Ree, M. Novel digital nonvolatile memory devices based on semiconducting polymer thin films. Adv. Funct. Mater. 17, 2637-2644 (2007).

22 Nam, S., Ko, Y.-G., Hahm, S. G., Park, S., Seo, J., Lee, H., Kim, H., Ree, M. \& Kim, Y. Organic nonvolatile memory transistors with self-doped polymer energy well structures. NPG Asia Mater. 5, e33 (2013).

23 Park, S., Lee, T. J., Kim, D. M., Kim, J. C., Kim, K., Kwon, W., Ko, Y.-G., Choi, H., Chang, T. \& Ree, M. Electrical memory characteristics of a non-doped $\pi$-conjugated polymer bearing carbazole moieties. J. Phys. Chem. B 114, 10294-10301 (2010).

24 Ko, Y.-G., Kwon, W., Kim, D. M., Gal, Y.-S. \& Ree, M. Programmable nonvolatile electrical memory characteristics of an ionic conjugated polymer. Polym. Chem. 3, 2028-2033 (2012).

25 Ko, Y.-G., Kim, D. M., Kim, K., Jung, S., Wi, D., Michinobu, T. \& Ree, M. Digital memory versatility of fully $\pi$-conjugated donor-acceptor hybrid polymers. ACS Appl. Mater. Interfaces 6, 8415-8425 (2014).

26 Ling, Q.-D., Chang, F.-C., Song, Y., Zhu, C.-X., Liaw, D.-J., Chan, D. S.-H., Kang, E.-T. \& Neoh, K.-G. Synthesis and dynamic random access memory behavior of a functional polyimide. J. Am. Chem. Soc. 128, 8732 (2006)

27 Hahm, S. G., Choi, S., Hong, S.-H., Lee, T. J., Park, S., Kim, D. M., Kwon, W.-S., Kim, K., Kim, O. \& Ree, M. Novel rewritable, non-volatile memory devices based on thermally and dimensionally stable polyimide thin films. Adv. Funct. Mater. 18 3276-3282 (2008).

28 Kurosawa, T., Higashihara, T. \& Ueda, M. Polyimide memory: a pithy guideline for future applications. Polym. Chem. 4, 16-30 (2013).

29 Hahm, S. G., Kang, N.-G., Kwon, W., Kim, K., Ko, Y.-G., Ahn, S., Kang, B.-G., Chang, T., Lee, J.-S. \& Ree, M. Programmable bipolar and unipolar nonvolatile memory devices based on poly(2-( $N$-carbazolyl)ethyl methacrylate) end-capped with fullerene. Adv. Mater. 24, 1062-1066 (2012).

30 Kim, Y. Y., Ree, B. J., Kido, M., Ko, Y.-G., Ishige, R., Hirai, T., Wi, D., Kim, J., Kim, W. J., Takahara, A. \& Ree, M. High performance n-type electrical memory and morphology-induced memory-mode tuning of a well-defined brush polymer bearing perylene diimide moieties. Adv. Electron. Mater. (e-pub ahead of print 26 August 2015; doi: 10.1002/aelm.201500197).

31 Kim, G., Park, S., Jung, J., Heo, K., Yoon, J., Kim, H., Kim, I. J., Kim, J. R., Lee, J. I. \& Ree, M. Novel brush polymers with phosphorylcholine bristle ends: synthesis, structure, properties, and biocompatibility. Adv. Funct. Mater. 19, 1631-1644 (2009).
32 Ree, M. Probing the self-assembled nanostructures of functional polymers with synchrotron grazing incidence X-ray scattering. Macromol. Rapid Commun. 35, 930-959 (2014).

33 Lee, B., Park, Y.-H., Hwang, Y., Oh, W., Yoon, J. \& Ree, M. Ultralow-k nanoporous organosilicate dielectric films imprinted with dendritic spheres. Nat. Mater. 4, 147-150 (2005)

34 Bolze, J., Ree, M., Youn, H. S., Chu, S.-H \& Char, K. Synchrotron X-ray reflectivity study on the structure of templated polyorganosilicate thin films and their derived nanoporous analogues. Langmuir 17, 6683-6691 (2001).

35 Park, B.-J., Rah, S.-Y., Park, Y.-J. \& Lee, K.-B. PLS bending magnet X-ray beamline 3C2. Rev. Sci. Instrum. 66, 1722-1724 (1995).

36 Oh, W., Hwang, Y., Shin, T. J., Lee, B., Kim, J.-S., Yoon, J., Brennan, S., Mehta, A. \& Ree, M. Synchrotron X-ray reflectivity studies of nanoporous organosilicate thin films with low dielectric constants. J. Appl. Crystallogr. 40, S626-S630 (2007).

37 Kiessig, H. Interferenz von röntgenstrahlen an dünnen schichten. Ann. Phys. 10, 769-788 (1931).

38 Parratt, L. G. Surface studies of solids by total reflection of X-rays. Phys. Rev. 95, 359-369 (1954)

39 Campbell, A. J., Bradley, D. D. C. \& Lidzey, D. G. Space-charge limited conduction with traps in poly(phenylene vinylene) light emitting diodes. J. Appl. Phys. 82, 6326 (1997).

40 Jensen, K. L. Electron emission theory and its application: Fowler-Nordheim equation and beyond. J. Vac. Sci. Technol. B 21, 1528-1544 (2003).

41 Mark, P. \& Helfrich, W. Space-charge-limited currents in organic crystals. J. Appl. Phys. 33, 205-215 (1962).

42 Frenkel, J. On pre-breakdown phenomena in insulators and electronic semi-conductors. Phys. Rev. 54, 647-648 (1938).

43 Laurent, C., Kay, E. \& Souag, N. Dielectric breakdown of polymer films containing metal clusters. J. Appl. Phys. 64, 336-343 (1988).

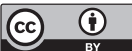

This work is licensed under a Creative Commons Attribution 4.0 International License. The images or other third party material in this article are included in the article's Creative Commons license, unless indicated otherwise in the credit line; if the material is not included under the Creative Commons license, users will need to obtain permission from the license holder to reproduce the material. To view a copy of this license, visit http:// creativecommons.org/licenses/by/4.0/

Supplementary Information accompanies the paper on the NPG Asia Materials website (http://www.nature.com/am) 